NBER WORKING PAPER SERIES

\title{
CAN FOREIGN EXCHANGE INTERVENTION STEM EXCHANGE RATE PRESSURES FROM GLOBAL CAPITAL FLOW SHOCKS?
}

\author{
Olivier Blanchard \\ Gustavo Adler \\ Irineu de Carvalho Filho \\ Working Paper 21427 \\ http://www.nber.org/papers/w21427
NATIONAL BUREAU OF ECONOMIC RESEARCH
1050 Massachusetts Avenue
Cambridge, MA 02138
July 2015

This work has benefited at different stages from comments and valuable conversations with Ahuja Ashvin, Tam Bayoumi, Jorge Braga de Macedo, Marcos Chamon, Varapat Chensavasdijai, Luca Dedola, José De Gregorio, Sebastian Edwards, Jeff Frankel, Rex Ghosh, Roberto Guimarães, Olivier Jeanne, Sebnem Kalemli-Ozcan, Martin Kaufman, Ruy Lama, Márcio Laurini, Nan Li, Kenji Moriyama, Christopher Neely, Jonathan Ostry, Steven Phillips, Helene Poirson, Ubirajara da Silva and Yossi Yakhin; as well as feedback from participants at various IMF seminars, the 2014 SNB Conference on "Exchange Rates and External Adjustment", the EMG-ECB 4th Emerging Markets Group Conference, the LACEA 2014 Annual Conference, and the 2015 NBER Summer Institute . We also thank Jair Rodriguez and Mauricio Vargas for their research assistance. Irineu de Carvalho Filho benefited from the hospitality of the Swiss National Bank and Georgetown University School of Foreign Service in Qatar. Remaining errors are ours. The views expressed in this paper are those of the authors and do not necessarily represent the views of the IMF, its Executive Board, IMF management, or the National Bureau of Economic Research.

NBER working papers are circulated for discussion and comment purposes. They have not been peerreviewed or been subject to the review by the NBER Board of Directors that accompanies official NBER publications.

(C) 2015 by Olivier Blanchard, Gustavo Adler, and Irineu de Carvalho Filho. All rights reserved. Short sections of text, not to exceed two paragraphs, may be quoted without explicit permission provided that full credit, including $\odot$ notice, is given to the source. 
Can Foreign Exchange Intervention Stem Exchange Rate Pressures from Global Capital Flow Shocks?

Olivier Blanchard, Gustavo Adler, and Irineu de Carvalho Filho

NBER Working Paper No. 21427

July 2015

JEL No. F31,F38,F41

\begin{abstract}
Many emerging market economies have relied on foreign exchange intervention (FXI) in response to gross capital inflows. In this paper, we study whether FXI has been an effective tool to dampen the effects of these inflows on the exchange rate. To deal with endogeneity issues, we look at the response of different countries to plausibly exogenous gross inflows, and explore the cross country variation of FXI and exchange rate responses. Consistent with the portfolio balance channel, we find that larger FXI leads to less exchange rate appreciation in response to gross inflows.
\end{abstract}

Olivier Blanchard

International Monetary Fund

Economic Counsellor and Director

Research Department

700 19th Street, NW

Rm. 10-700

Washington DC, 20431

and NBER

blanchar@mit.edu

Gustavo Adler

Research Department

International Monetary Fund

gadler@imf.org
Irineu de Carvalho Filho

Research Department

International Monetary Fund

IdeCarvalhoFilho@imf.org 


\section{INTRODUCTION}

Large capital flows have dominated the emerging market landscape in recent years, posing sizeable challenges to policy makers as they have tried to cope with the collateral effects of these flows, from asset price inflation, to credit booms, to overheating, to real exchange rate appreciation, and to the buildup of financial vulnerabilities. To lean against capital inflows, policymakers have increasingly relied on macro- and micro-prudential measures, regulation/deregulation of capital flows and foreign exchange market intervention (FXI). However, the effects of many of these policies — let alone their desirability_remain under debate, especially with regard to FXI. This is the focus of our paper.

Two motives have been offered to explain the use of FXI in response to capital inflows and the resulting increase in reserves. The first is a precautionary motive: Emerging market economies built up their cushions of foreign exchange needed in case of liquidity shortages (Aizenman and Lee, 2008; Jeanne and Ranciere, 2011; Ghosh, Ostry and Tsangarides, 2012). The second is a macro-management motive: FXI was deployed to moderate or avoid nominal or real appreciation pressures (e.g. Reinhart and Reinhart, 2008; Aizenman and Lee, 2008; Adler and Tovar, 2014; Gagnon, 2012). ${ }^{1}$

There is little controversy about the merits of FXI for precautionary motives (although there is still much debate about the optimal level of reserve buffers). On the contrary, whether FXI is effective in stemming exchange rate pressures remains an open question and an empirical challenge (under the precautionary motive, it does not matter whether FXI affects the exchange rate or not).

Most economists agree that unsterilized intervention is effective at influencing the exchange rate (as it entails a change in the monetary policy stance), but the case for effectiveness of sterilized intervention is less obvious on both theoretical and empirical grounds. In theory, sterilized

\footnotetext{
${ }^{1}$ The specific reasons for intervening in foreign exchange markets have been the subject of several studies (e.g. Canales-Kriljenko, 2003; Moreno, 2005; Neely, 2008), and include influencing the level of the exchange rate, dampening exchange rate volatility, preventing excessive exchange rate movements or overshooting, supplying liquidity during periods of market disruption (Stone, Walker and Yasui, 2009), and leaning against the wind.
} 
intervention can affect the exchange rate through a signaling channel (FXI informs about the central bank's monetary policy intentions) or a portfolio balance channel (which operates under imperfect substitutability between domestic and foreign assets). While relevant as a mechanism to affect the exchange rate, the signaling channel has received relatively limited attention as it implies that FXI is not an extra policy instrument but, rather, a way to signal intentions regarding other existing policy tools. The portfolio balance channel, on the other hand, has received more attention since the theoretical underpinnings were developed by Henderson and Rogoff (1982), Kouri (1983), and Branson and Henderson (1985). ${ }^{2}$

From an empirical perspective, estimating the effect of (sterilized) intervention on the exchange rate has been a major methodological challenge for the literature, as the decision to intervene is often driven by contemporaneous exchange rate developments, and is thus endogenous. See, for example, the extensive work on FXI in advanced economies by Dominguez (1990 and 1998); Dominguez and Frankel (1990, 1993a, 1993b and 1993c), and Ghosh (1992); and more recently on emerging market economies by Tapia and Tokman, 2004; Guimarães and Karacadağ, 2004; Domaç and Mendoza, 2004; Humala and Rodriguez, 2010; Kamil, 2008; Rincón and Toro, 2011; Dominguez, Fatum and Vacek, 2013). Unaddressed, the endogeneity bias tends to conceal the effect of FXI on the exchange rate. Thus, it is not surprising that the evidence about the effect of FXI on the exchange rate remains mixed. Most of the literature has attempted either an instrumental variable approach (seeking exogenous variations of FXI) or relied on high frequency (including minute-by-minute) time-stamped data. In the first case, finding proper instruments has been a major challenge. In the second case, using data that is sampled at a higher frequency than the decision to intervene has allowed researchers to break the reverse causality, and find evidence that intervention does influence the level of exchange rates. However, highfrequency estimates are not informative about the persistent and cumulative effects of intervention, which are of paramount importance for the macroeconomist and the policy maker.

\footnotetext{
${ }^{2}$ See Kumhof (2010) and Gabaix and Maggiori (2014) for recent advances in the theory of the portfolio balance channel.
} 
Our paper takes a different approach. Relying on country-specific VAR estimations, our empirical strategy relies on the exogenous nature of global capital flows from the point of view of each small open economy, and exploits the cross-section variation of FXI responses to these exogenous shocks. The evidence suggests that FXI is effective in stemming appreciation pressures arising from global flow shocks. The effect is of economically meaningful magnitude, indicating that — while its relative merits are yet to be assessed — FXI can be a valid policy tool for macroeconomic management.

The paper relates to several strands of research:

It relates, of course, to the growing literature on the role and effects of sterilized FXI in emerging countries, which has taken theoretical, empirical and policy angles. See, for example, the comprehensive reviews of the literature on FXI in Sarno and Taylor (2001), Neely (2005) and Menkhoff (2010 and 2012) and the recent contributions by Benes, Berg, Portillo and Vavra (2012), Ghosh, Ostry and Chamon (2015), Gagnon (2013), and Bayoumi, Gagnon and Saborowski (2014). It relates also to the empirical literature on the effect of global financial conditions on emerging market economies, dating back to Calvo, Leiderman and Reinhart (1993), who study the role of push factors in driving inflows to Latin American countries; Hau, Massa and Peress (2009), who show how exogenous portfolio equity inflows cause exchange rate appreciation in the receiving countries; and Rey (2013), who argues that global financial conditions are transmitted to financially integrated economies irrespective of their exchange rate regime (thus reducing monetary policy independence unless the capital account is managed). A common thread in this literature is that global financial conditions can have pervasive effects on emerging market economies, including through the impact on exchange rates. If effective, sterilized intervention becomes a key policy instrument for managing capital flows.

The rest of the paper is organized as follows: Section II presents a simple model with imperfect asset substitutability to discuss the theoretical underpinnings of the following empirical exercise. Section III explains the empirical strategy, along with the main results and a number of robustness checks. Section IV concludes. 


\section{A Linear Model of the Portfolio Balance Channel}

It is useful to start by presenting a simple model with imperfect substitutability between domestic and external assets, which illustrates the workings of foreign exchange interventionthrough a portfolio balance channel — in the context of (exogenous) capital inflow shocks. The predictions of this simple model can then be used to interpret the empirical evidence in section III.

We follow the terminology used in recent papers, calling gross inflows the net movement in international liabilities of a country, and gross outflows the net movement in international assets (note that both "gross inflows" and "gross outflows" can be negative). We interpret gross inflows as reflecting primarily the decisions of foreign investors to change their holdings of domestic assets; and gross outflows as reflecting mainly the decisions of domestic investors to change their holdings of foreign assets. ${ }^{3}$

Let GPKI denote gross (private) inflows and GPKO denote gross (private) outflows. Let $F X I$ be foreign exchange intervention (defined as reserve sales), and $C A$ the current account balance. The balance of payment identity implies that:

$$
G P K I_{j, t}-G P K O_{j, t}+F X I_{j, t}+C A_{j, t}=0
$$

Assume the following linear functional forms for GPKI and GPKO respectively, allowing for a departure from uncovered interest rate parity (UIP):

$$
\begin{aligned}
& G P K I_{j, t}=\alpha\left(i_{j, t}-i_{t}^{*}-e_{j, t}+E e_{j, t+1}\right)+z_{t} \\
& G P K O_{j, t}=-\beta\left(i_{j, t}-i_{t}^{*}-e_{j, t}+E e_{j, t+1}\right)-\rho z_{t}
\end{aligned}
$$

\footnotetext{
${ }^{3}$ For more on the nature of these gross flows, see for example, Powell et al. (2002), Cowan et al (2008), Rothenberg and Warnock (2011), Forbes and Warnock (2012), Bruno and Shin (2012), Calderón and Kubota (2013), Bluedorn et al (2013), Cavallo et al (2013), Broner et al (2013), and Alberola et al (2013).
} 
where $i_{j, t}$ is the domestic interest rate, $i_{t}^{*}$ is the interest rate on foreign assets, $e_{j, t}$ is the exchange rate (an increase being an appreciation), and $z_{t}$ stands for the set of exogenous variables driving global capital flows (e.g., risk appetite). Assume the current account is a also simple linear function of the exchange rate $C A_{j, t}=-\gamma e_{j, t}$ (with $\left.\gamma \geq 0\right){ }^{4}$

The parameters $\alpha$ and $\beta$ reflect the sensitivity of gross inflows and outflows to rate of return differentials. The parameter $\rho$ reflects how reactive domestic investors are to global financial shocks (relative to foreign investors, whose sensitivity is normalized to one). As a full-fledged portfolio model would predict, and consistent with the empirical evidence, $\alpha$ and $\beta$ are expected to be positive, indicating that gross flows move in the same direction when arbitraging deviations from UIP, although possibly with different sensitivities. Theory does not deliver a prior on the sign of $\rho$. If we think of $z_{t}$ as reflecting primarily movements in risk appetite, the sign depends on whether lower risk appetite leads domestic investors to move in the same direction as foreign investors, in which case $\rho$ is positive and gross outflows amplify the behavior of gross inflows, or if it leads instead domestic and foreign investors to move in opposite directions, both to 'return home', in which case $\rho$ is negative, and gross outflows partly offset the effects of gross inflows. The evidence below, together with other recent empirical evidence, suggests that the second case is the relevant one (that is, for most countries, higher market risk aversion reinforces home bias and leads both foreign and domestic investors to repatriate assets in their own country). ${ }^{5}$

We capture the two key dimensions of the central bank response to flows through the following two equations:

$$
\begin{aligned}
& i_{j, t}-i_{t}^{*}=-d e_{j, t} \\
& F X I_{j, t}=-(1+\rho) \phi z_{t}
\end{aligned}
$$

\footnotetext{
${ }^{4}$ Since we are interested in the short-term impact of capital inflows, our simplified model does not consider the cumulative effect of the current account on the net international investment position. Those considerations would be warranted if we were to focus on medium-term effects.

${ }^{5}$ See, for example, Adler et al (2015).
} 
We assume that the domestic interest rate, $i_{j, t}$, responds to the exchange rate, $e_{j, t}$, and that the parameter $d$ can be positive or negative. We model FXI as an offset (proportion $\phi$ ) to the exogenous component of net private capital flows, $(1+\rho) z_{t}$.

Finally, we assume global capital flow shocks, $z_{t}$, follow an $A R(1)$ process with coefficient $\psi$.

Then, combining equations (1)-(5) yields the equilibrium conditions: ${ }^{6}$

$$
\begin{gathered}
e_{j, t}=\frac{(1+\rho)(1-\phi)}{(\alpha+\beta)(1+d-\psi)+\gamma} z_{t} \\
G P K I_{j, t}=\left[1-\frac{\alpha(1+\rho)(1-\phi)(1+d-\psi)}{(\alpha+\beta)(1+d-\psi)+\gamma}\right] z_{t} \\
\text { GPKO }_{j, t}=\left[\frac{\beta(1+\rho)(1-\phi)(1+d-\psi)}{(\alpha+\beta)(1+d-\psi)+\gamma}-\rho\right] z_{t} \\
F X I_{j, t}=-(1+\rho) \phi z_{t}
\end{gathered}
$$

Assume $\gamma \leq \bar{\gamma}$, with $\underline{\gamma} \equiv-(1+d-\psi)\left[(\alpha+\beta)-\beta \frac{(1+\rho)(1-\phi)}{\rho}\right]$. That is, the current account exchange rate elasticity is sufficiently low. It follows, from equation (6), that the domestic currency appreciates in response to a positive gross inflow shock. The central bank can dampen the effect of the shock on the exchange rate in two ways: by decreasing the interest rate $(d$ positive), or by using FXI ( $\phi$ positive).

\footnotetext{
${ }^{6}$ Note that the persistence of the capital flow shock $(\psi)$ affects the contemporaneous response of the exchange rate to $z$ (i.e., the higher is the expected persistence of the capital flow shock, the more the domestic currency appreciates) but not the response of the gross flows.
} 


\section{The effect of FXI}

Figure 1 presents comparative statics on the effects of the shock $z_{t}$ on the exchange rate and gross flows, with respect to the degree of FXI $(\phi)$; focusing on the case of imperfect asset substitutability (i.e., $\alpha$ and $\beta$ take finite values). ${ }^{7}$

The left panel shows the effect of intervention on the exchange rate. Intervention dampens the effect of the external shock on the exchange rate, so long as private domestic investors do not fully play that offsetting role themselves (i.e., $\rho>-1$ ). In the limiting case of $\rho=-1$, where domestic investors mirror perfectly the foreigners' reaction to the global shocks, intervention is unnecessary.

The middle panel shows the effect of intervention on gross inflows and outflows. Gross inflows increase and gross outflows decrease with the degree of intervention (and the vertical distance between the two lines gives the extent of intervention). This is because the higher the degree of intervention, the lower the initial appreciation and so the lower the expected depreciation later on. As a result, the more attractive it is for foreign investors to buy domestic assets, and for domestic investors to stay home. In the case of no intervention, the exchange rate moves to induce gross outflows and the current account to offset the response of gross inflows. In the case of full intervention, the exchange rate does not change, and gross inflows and outflows are thus equal to $z$ and $-\rho z$ respectively, with intervention equal to net private inflows $(1+\rho) z$.

\footnotetext{
${ }^{7}$ The case of perfect substitution between domestic and foreign assets corresponds to the limit case of $\alpha \rightarrow \infty$ and/or $\beta \rightarrow \infty$; and it is straightforward to show that $\lim _{\alpha \rightarrow \infty} d e / d z=\lim _{\beta \rightarrow \infty} d e / d z=0$.
} 
Figure 1. Portfolio Balance Channel-Effect of FXI
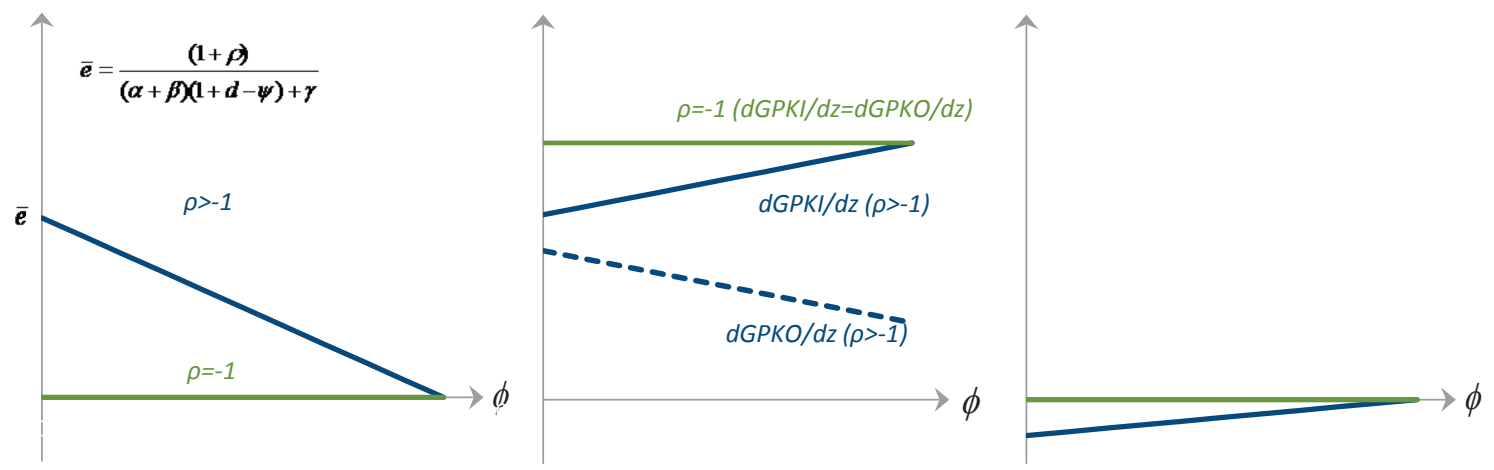

Note: comparative statics with parameterization: $\alpha=\beta=0.5, \psi=0.2, \gamma=0.2$, and $d=0$, unless indicated otherwise.

With the empirical results below in mind, Figure 2 presents the dynamic responses to a shock to $z_{t}$ derived from the model, comparing the case of no intervention $(\phi=0)$ and relatively heavy intervention ( $\phi=.5)$, serving as a benchmark illustration to compare to our empirical findings. For a given value of $\rho>-1$, a higher degree of intervention dampens the impact of the shock on the exchange rate, while inducing a gap between gross inflows and gross outflows, increasing the former and reducing the later. The effects fade away as the external shock $z_{t}$ does. In this example (consistent with our later empirical findings) interest rates do not respond to the shock, and so the differential impact on the exchange rate can be fully attributed to FXI through a portfolio balance channel.

Figure 2. Portfolio Balance Channel-Dynamic Responses

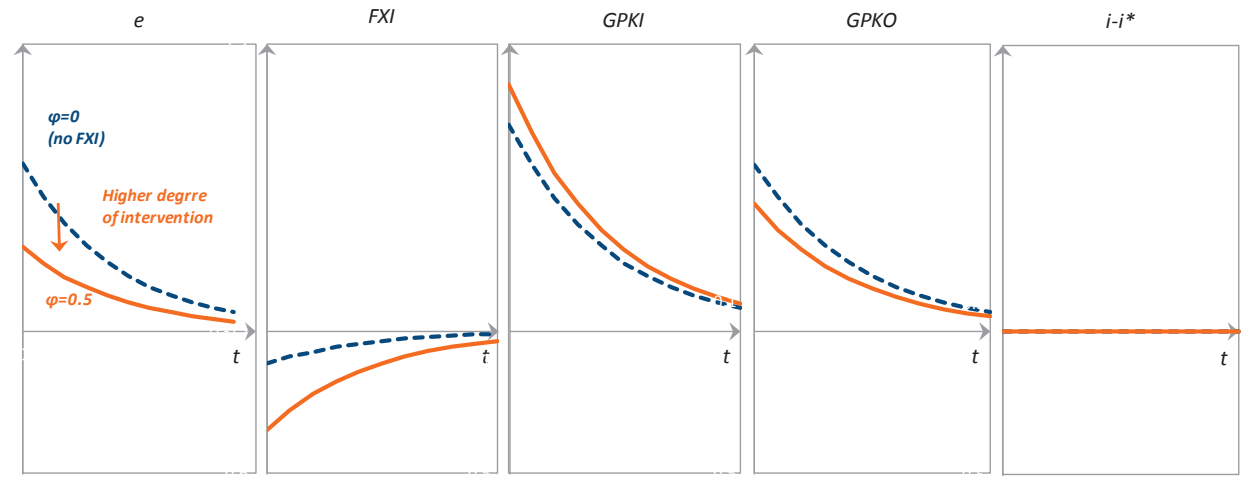

Note: comparative statics with parameterization: $\alpha=\beta=0.5, \psi=0.2, \gamma=0.2, \rho=$ -0.3 and $d=0$, unless indicated otherwise. 
This simple model illustrates the workings of the portfolio balance channel, pointing to some testable predictions: (i) a positive exogenous global financial (risk appetite) shock leads to an appreciation of the domestic currency; (ii) gross capital inflows increase and so, if $\rho$ is negative, do gross outflows; (iii) FX intervention mitigates the effect of the shock on the exchange rate; and (iii) larger interventions are accompanied by larger gross inflows and/or smaller gross outflows.

Next we contrast these predictions with our empirical findings.

\section{EMPIRICAL EVIDENCE}

\section{A. Methodological Approach}

Our empirical approach relies on the largely exogenous character of global capital flows from the point of view of any one of the small emerging and advanced open economies. ${ }^{8}$ Under the assumption that global capital flows are indeed exogenous to each country, we then estimate the response of FXI, gross inflows, gross outflows, the interest rate and the exchange rate to these flows, on a country by country basis. We can then classify countries into groups based on their de facto FXI reaction function and explore the cross-sectional dimension by comparing differences across country groups.

Specifically, to identify the effect of sterilized intervention on exchange rates, we estimate country-specific VARs linking the key variables identified in the previous section. The specification for each country takes the following functional form:

$$
\left(I-A_{1} L-\ldots-A_{p} L^{p}\right) Y_{j, t}=\varepsilon_{j, t}
$$

where $L^{p}$ denotes a lag operator of order $p, A_{1} \ldots A_{p}$ are $6 \times 6$ parameter matrices, and $Y_{j, t}$ is the vector of endogenous variables defined as:

\footnotetext{
8 The existence of global financial flows, sometimes referred to as a "global financial cycle", has been previously documented in the literature (e.g. Calvo, Leiderman and Reinhart, 1993) and has been used as a working assumption in a variety of studies (e.g. Agénor, Alper and Pereira da Silva, 2012; De Bock and de Carvalho Filho, 2015; de Carvalho Filho, 2014; Rey, 2013).
} 


$$
Y_{j, t} \equiv\left[\begin{array}{c}
E R_{j, t} \\
F X I_{j, t} \\
G P K I_{j, t} \\
G P K O_{j, t} \\
I N T_{j, t} \\
G K F_{j, t}
\end{array}\right]
$$

where $E R_{j, t}$ denotes the log of the nominal exchange rate vis-a-vis the U.S. in the benchmark specification (although we also explore a model with the real exchange rate as an extension later); $F X I_{j, t}$ refers to $\mathrm{FX}$ intervention, measured as net reserve sales (so reserve accumulation appears as a decrease in FXI, following the balance of payments definition) plus changes in the central bank off balance sheet FX position. This broad measure of FXI allows us to capture the increasing use of non-spot interventions seen in recent years; ${ }^{9,10} G P K I_{j, t}$ and $G P K O_{j, t}$ denote country $j$ 's gross private capital inflows and outflows, respectively. All flow variables are normalized by lagged gross domestic product in U.S. dollars for comparability (using lagged rather than actual GDP to deal with the potential endogeneity of actual GDP) and are reported as annualized flows. $I N T_{j, t}=i_{j, t}-i_{t}^{*}$ is the short-term interest rate differential with respect the U.S. ${ }^{11}$

\footnotetext{
${ }^{9}$ Off balance sheet items are composed of short and long positions in forwards and futures in foreign currencies visà-vis the domestic currency (including the forward leg of currency swaps), and financial instruments denominated in foreign currency but settled by other means (e.g., in domestic currency), as reported in the International Reserves and Foreign Currency Liquidity Template. Coverage of off balance sheet positions varies across countries, but is sufficiently comprehensive to capture large derivate transactions of recent years. Still, we conduct robustness checks on the proxy of FXI in Section III.C.

${ }^{10}$ In the system of balance of payments accounts, a gross inflow, namely the purchase of a domestic asset by a nonresident, may ultimately generate four different outcomes (or combinations thereof): (a) if the resident seller of the domestic asset - she - holds to the foreign currency proceeds of the asset sale or swaps it for a foreign asset, there is an equivalent 'gross outflow'; (b) if she sells the foreign currency proceeds to another resident who uses it to buy foreign assets, there is also an equivalent 'gross outflow'; (c) if she uses those proceeds to consume, or sells the foreign currency to another resident who buys foreign goods, there is an ultimate impact on the current account balance; and (d) if she sells the foreign currency, directly or indirectly, to the central bank, there is a negative net reserve sale or 'reserve accumulation'.

${ }^{11}$ For most countries, the short-term interest rate is the policy rate from Global Data Source (GDS), but as dictated by data availability, we used for a few countries the lending rate from International Financial Statistics (Bolivia, Croatia, Guatemala, Sri Lanka, Indonesia, Mexico, Malaysia and Romania).
} 
By including the interest rate differential, we control for the effect of contemporaneous changes in the monetary policy stance (unsterilized FXI).

Finally, $G K F_{j, t}$ denotes our exogenous measure of aggregate (global) gross capital flows for country $j$. For each country $j$, the measure is constructed as the sum of gross private capital inflows to all non-reserve currency countries in our sample leaving out country $j$, divided by the sum of corresponding nominal GDPs in U.S. dollars. ${ }^{12}$

Data on gross private capital flows come from the Financial Flows Analytics database compiled by the IMF Research department. Gross private capital flows are constructed by adding FDI in the reporting economy and the private elements of portfolio investment, financial derivative transactions and other investment gross flows from the perspective of the originator of the funds. Algebraically, our measure of global capital flows is given by:

$$
G K F_{j t}=\frac{\sum_{i \in \Theta \backslash j} G P K I_{i t}}{\sum_{i \in \Theta \backslash j} G D P_{i, t-1}^{U S D}}
$$

where $\Theta$ denotes the set of all non-reserve currency countries for which balance of payments and GDP data is available on a quarterly basis (and $\Theta \mid j$ denotes the set excluding country $j$ ); $G D P_{i, t-1}^{U S D}$ is gross domestic product measured in U.S. dollars from the IMF's WEO database; and $G P K I_{i t}$ denotes the gross inflows for country $i$, as defined above. Figure 3 (blue dots) shows the time series of this measure for all countries in the sample. While this variable is country-specific, as shown by the vertical (cross-section) variation, there is a clear common global cycle, with pronounced variations especially during the 2008-09 global crisis. ${ }^{13}$ This measure of global flows correlates closely with measures of market risk aversion, like the Chicago Board Options Exchange Market Volatility (VIX) Index (chart to the left), suggesting that risk appetite may be

\footnotetext{
${ }^{12}$ The United States, United Kingdom, Switzerland, Japan and the members of the Euro Area are excluded as they issue reserve currencies.

${ }^{13}$ See Milesi-Ferretti and Tille (2011) for a detailed documentation of the latter phenomenon.
} 
the main common factor at play, while it displays little correlation with the U.S. policy interest rate (chart to the right).

Figure 3. Country-specific Measure of Global Capital Flows, VIX and US Interest Rate
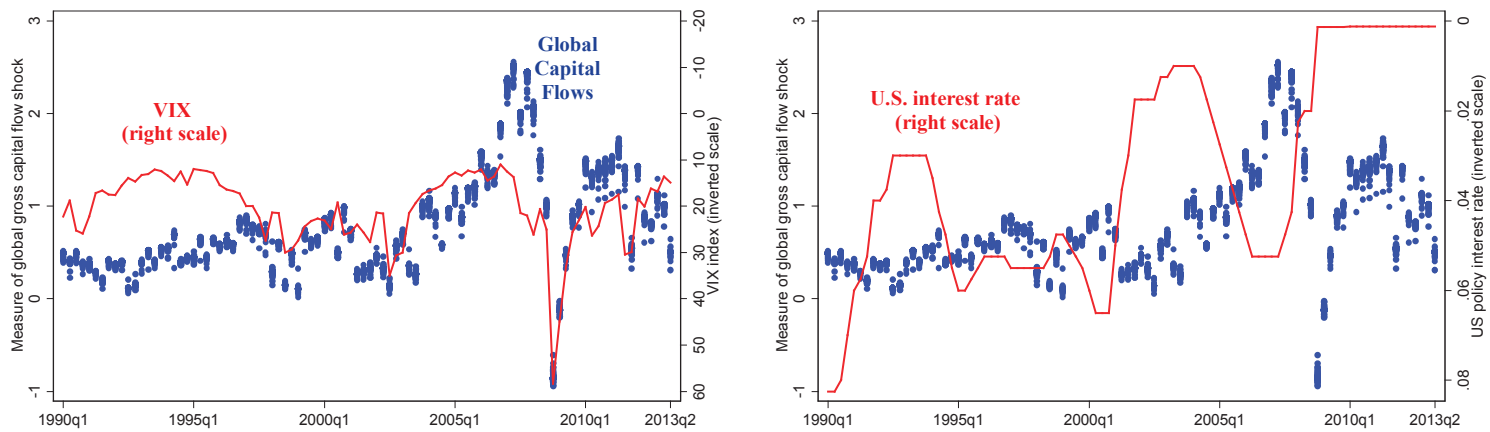

Source: Bloomberg and authors' calculations.

Note: Both the VIX index and the U.S. monetary policy rate are reported in inverted scale, as one would expect a negative correlation, if any, between these variables and the measure of global capital flows.

The sample includes 35 emerging market and advanced economies, based on data availability. ${ }^{14}$ Economies whose central banks issue a reserve currency (US, United Kingdom, Japan, Switzerland and members of the Euro area) are excluded from the sample. The sample covers quarterly data for the period 1990Q1-2013Q4, although it is restricted, on a country-by-country basis, by data limitations. Furthermore, as our empirical strategy relies on classifying countries according to their FXI behavior, as explained in detail below, we also exclude certain countryspecific time periods in order to rule out structural breaks related to changes in monetary and exchange rate regimes during the estimation time window (see Appendix Table A1). For each country, the number of lags in the VAR specification, averaging 2.5, is chosen based on the Akaike information criterion (this implies, for a country for which data exist back to 1990, an average of 81 degrees of freedom)

\footnotetext{
${ }^{14}$ Those are Australia, Bolivia, Brazil, Bulgaria, Canada, Chile, China: Mainland, Colombia, Croatia, Czech Republic, Denmark, Estonia, Guatemala, Hungary, India, Indonesia, Israel, Korea, Latvia, Lithuania, Malaysia, Mexico, New Zealand, Norway, Peru, Philippines, Poland, Romania, Russia, South Africa, Sri Lanka, Sweden, Thailand, Turkey and Ukraine.
} 


\section{B. Main Results}

Our interest lies in the estimated responses of the domestic variables to the exogenous capital flow shock GKF. Figure 4 displays impulse response functions to a one-standard deviation shock to our measure of global capital flows, for all non-peg countries in the sample. Panel (a) displays the median and the interquartile range of individual country impulse responses. Panel (b) displays the weighted average of the point estimates, together with the weighted averages of individual confidence (60\%) bands, with weights inversely proportional to the standard deviation of each impulse response.

Figure 4. Responses to a Global Capital Flows Shock

Panel (a). Cross-section variation of individual impulse responses
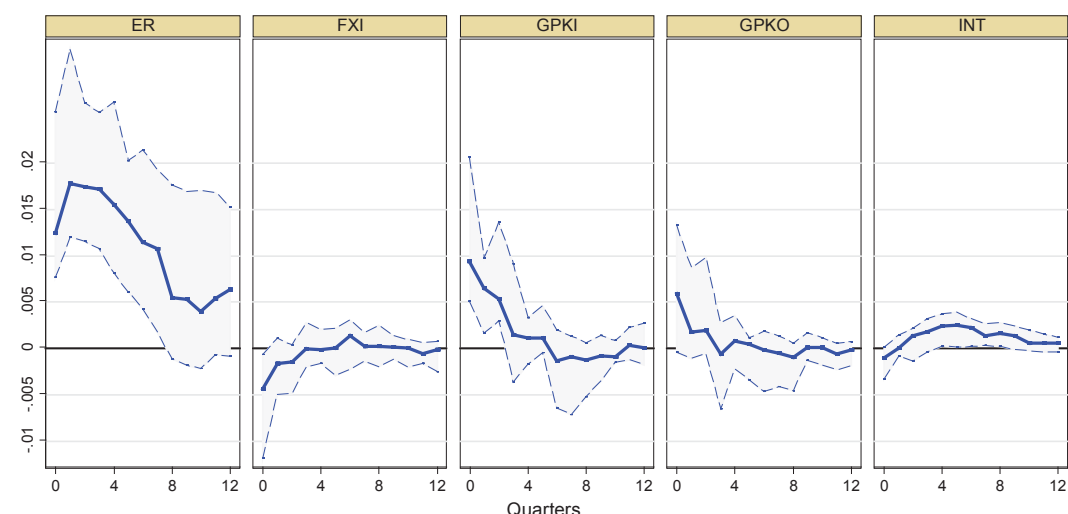

Panel (b). Weighted average of individual impulse responses
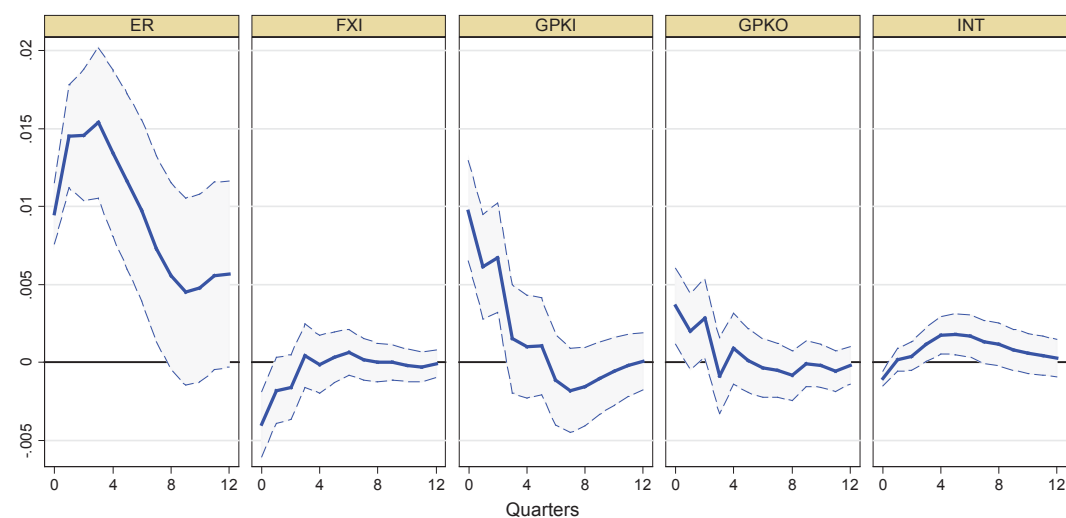

Note: The figure reports impulse response functions to a one standard deviation shock to the global capital flow variable. The upper panel displays the cross-section variation of responses for different countries, with the median and inter-quartile range. The lower panel shows a weighted average of impulse responses and their (60 percent) confidence bands, with weights that are inversely proportional to the standard deviation of each impulse response. 
These general results indicate that:

While there is a relatively wide range of exchange rate responses to the exogenous shocks, both panels indicate an unambiguous appreciation of the local currency, averaging about $1 \frac{1}{2}$ percent over the first 2 quarters, and gradually fading away.

As expected, gross private inflows increase in response to the positive GKF shock, reaching about 1 percent of GDP on impact and remaining (statistically) positive for about 3 quarters. Gross private outflows also increase, but less than inflows (suggesting a value of $\rho>-1$ ).

Most countries in the sample use FXI in response to the increase in gross inflows and accumulate reserves. Finally, short-term interest rate differentials display a fall in response to the shock, at least initially, but the effect is very small.

Figure 5 provides additional information on the individual country estimates for our main variables of interest (GPKI, ER, FXI), ${ }^{15}$ reporting cumulative impulse responses (point estimates and confidence bands) estimates on impact and at a 2-quarter horizon. For the exchange rate, non-cumulative responses are reported. The first panel points to the strength of global financial conditions in driving gross inflows to most countries in the sample. Indeed, we find evidence of a negative effect on impact for only one of the 27 non-peg economies (Norway); and there is no country with a negative cumulative impact at a 2-quarter horizon. The impact on exchange rates is also unequivocally positive, with all countries displaying positive effects on impact and 2quarter horizons. Finally, we find significant heterogeneity in the responses of FXI, although a large proportion of countries (20 out of 27) show reserve accumulation on impact, and the proportion increases to 22 out of 27 for a 2 -quarter horizon.

\footnotetext{
${ }^{15}$ Other variables are reported in the appendix.
} 
Figure 5. Responses to a Global Capital Flows Shock (non-peg economies)

Step $t=0$ Step $t=2$

Panel (a). GPKI responses
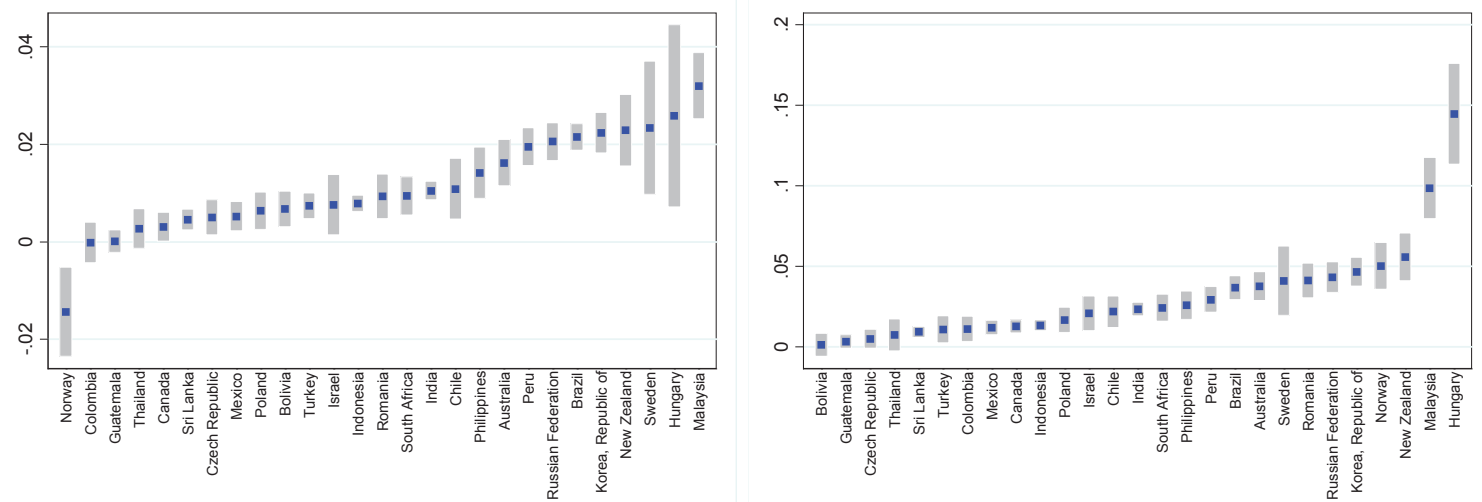

Panel (b). ER responses
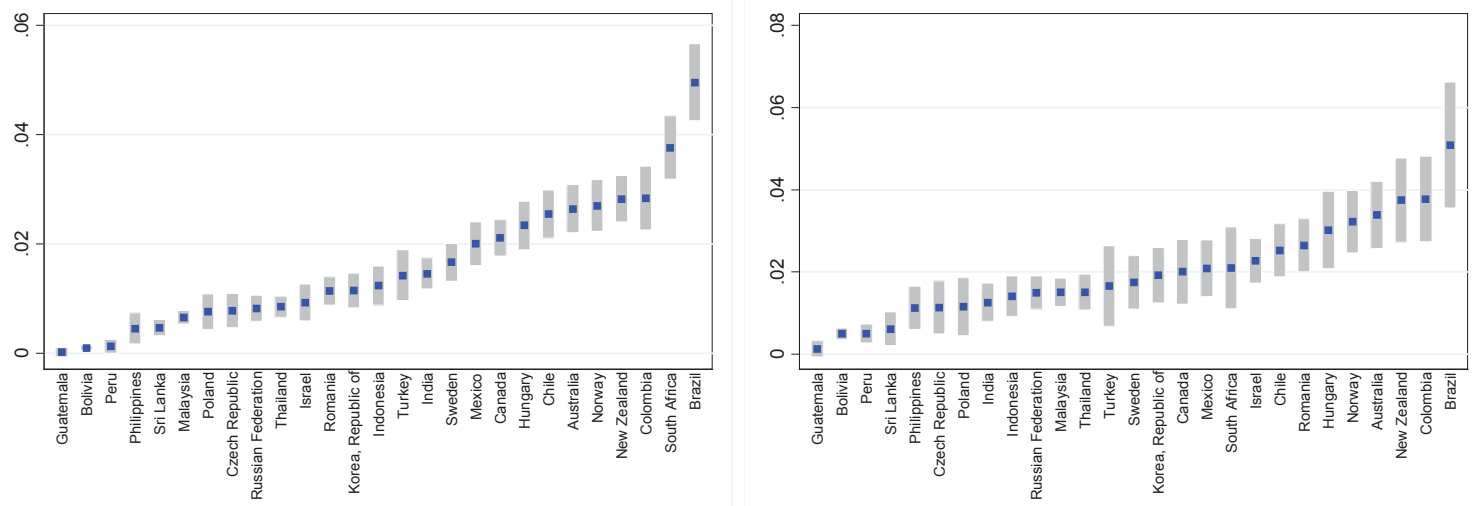

Panel (c). FXI responses
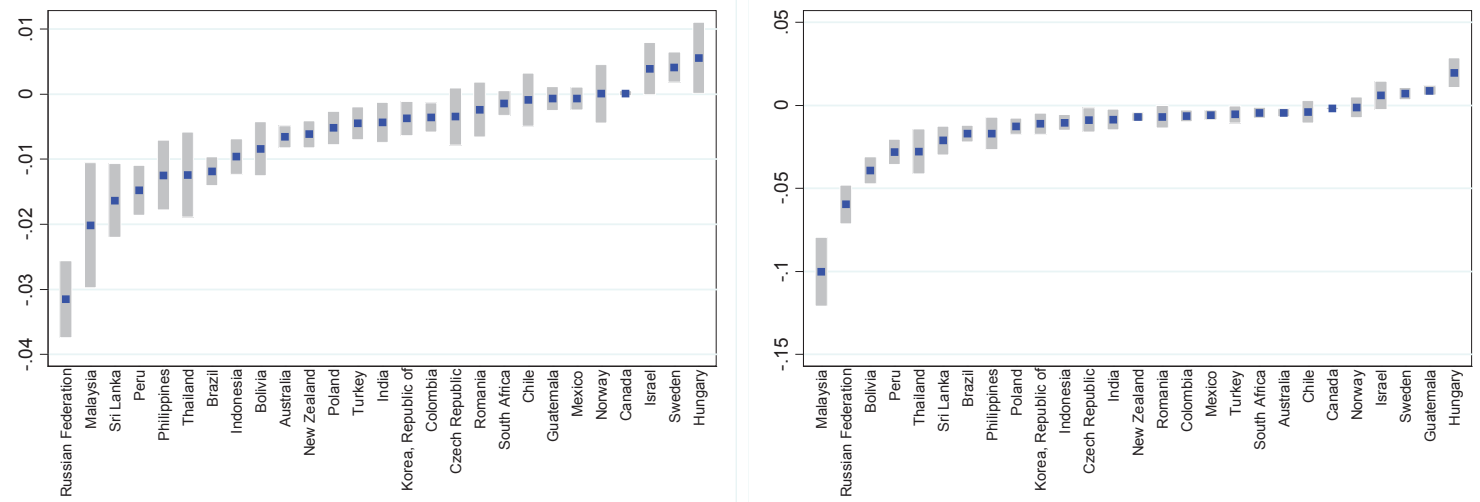

Note: Cumulative impulse (except for ER) responses from individually estimated VAR models, at $\mathrm{t}=0$ and $\mathrm{t}=2$. One standard deviation bands are reported. 


\section{De Facto FXI Regimes}

The significant cross-section variation in FXI responses potentially provides us with the evidence needed to look at the impact of these policies on the exchange rate. Specifically, to explore the cross sectional variation of the results, we construct a de-facto FXI regime classification by breaking the sample of countries down based on the individual responses to the global capital flows shock, according to the following criteria:

- We continue to exclude countries with de-facto pegs, as in Ilzetzki et al (2011). We include only economies if they show sensitivity to global capital flow shocks, based on whether any of the cumulative impulse responses of GPKI or FXI; or and the impulse response of $E R$ show a statistically significant impact (at a 2-quarter horizon).

- We group the remaining countries (countries with flexible exchange rate regimes and categorized as sensitive to global capital flows) in two groups, floaters or interveners, based on their cumulative FXI responses (i.e. whether they are smaller or larger than the median) at a 2-quarter horizon.

Table 1 presents the country grouping according to these criteria and the VAR estimations presented before:

Table 1. De Facto FXI Regime 1/

\begin{tabular}{|l|l|l|l|}
\hline \multirow{2}{*}{ De Facto Pegs 2/ } & \multicolumn{3}{|c|}{ Flexible Exchange Rate Regime 2/ } \\
\cline { 2 - 4 } & Not sensitive & Sensitive to the GFC \\
\cline { 2 - 3 } Bulgaria & to the GFC 3/ & Floaters 4/ & Interveners 4/ \\
China, P.R.: Mainland & & Australia & Bolivia \\
Croatia & & Canada & Brazil \\
Denmark & Chile & Czech Republic \\
Estonia & Colombia & India \\
Latvia & Hungary & Indonesia \\
Lithuania & & Korea \\
Ukraine & & Israel & Malaysia \\
& & Mexico & Peru \\
& & New Zealand & Philippines \\
& & Norway & Poland \\
& & Romania & Russian Federation \\
& & South Africa & Sri Lanka \\
& & Sweden & Thailand \\
\hline
\end{tabular}

Sources: Ilzetzki et al (2011); and authors' calculations.

1/ Based on FXI responses to a global capital flow shock. 2/ According to llzetzki et al (2011). 3/ Sensitivity to global capital flows is determined by the impulse responses of gross private capital inflows (GPKI), exchange rate (ER), and FXI. 4/ Based on degree of intervention, splitting sample in half.

\section{Flexible exchange rate regimes}

Most countries appear in the expected category, based on their known sensitivity to global financial conditions and their history of FXI during the sample period. It is important to stress that this classification relates to intervention policies in response to global capital flow shocks only. Some of the countries that are found not to respond to those shocks could in fact intervene significantly and frequently in response to other shocks, including idiosyncratic ones. 
Next, we analyze the responses of the key variables to a global capital flow shock, by comparing the groups of floaters and the group of interveners (we still do estimation country by country). Countries with fixed exchange rate regimes are initially excluded, as our benchmark specification focuses on the nominal exchange rate.

Figure 6 reports the weighted average impulse response functions and confidence bands for different variables for each of the two groups.

- The difference in FXI responses between the two groups is sizeable, close to 1 percent of quarterly GDP ( 0.25 percent of annual GDP) on impact.

- Interveners display a smaller appreciation of their currencies in response to the gross inflows. Specifically, we find a 1.5 percentage point differential in appreciation between interveners and floaters over the first 3-4 quarters. The differential fades afterwards. This difference is significant, both statistically and economically. We see this result—which seems fairly robust as shown below-as the main conclusion of the paper.

- Moreover, comparing the differential between the two groups of FXI and ER responses suggests a large effect of FXI: a quarterly annualized intervention of 1 percent of GDP (0.25 percent non annualized) leads to about 1.5 percent lower appreciation on impact.

- There is no evidence of a different interest rate behavior between the two groups, at least on average, suggesting that neither interveners nor floaters rely on the interest rate to 'defend' their exchange rates in response to exogenous capital flow shocks. 
Figure 6. Impulse Responses to a Global Capital Flow Shock

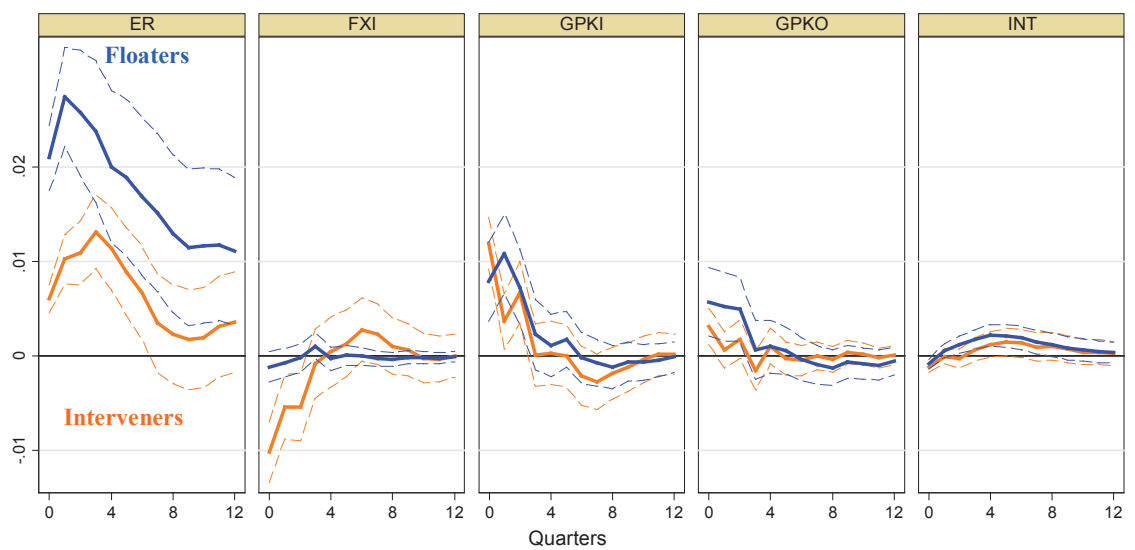

Note: Impulse response functions to a one standard deviation shock to the global capital flow variable. For each group, weighted averages of the impulse responses and confidence bands are reported, with weights that are inversely proportional to the standard deviation of each impulse response.

- Consistent with the predictions of the simple model presented earlier, gross capital inflows respond equally or more markedly in intervening countries, in comparison to floaters. Gross outflows increase for both groups, pointing to an offsetting role by domestic investors (a negative value of $\rho$ ), but more in floaters.

- There are two possible causal interpretations of the negative relation between the size of FXI and the size of gross outflows in response to shocks. The first follows from our model, and causality runs from FXI to gross outflows: Sterilized interventions limit the exchange rate appreciation, leading to a smaller expected depreciation, thus making it relatively less attractive for domestic investors to buy foreign assets. The second runs instead from gross outflows to the FXI response. It holds that, if domestic investors are less able or less willing to offset gross inflows, the central bank partly replaces them by using more FXI. We examined the issue by looking at the relation between various measures of the size and the depth of the domestic investor base, and did not find a robust relation between those measures and the strength of the response of gross outflows. This suggests that the causality runs from stronger FXI to smaller appreciation, to smaller outflows.

Figure 7 shows the cross section of exchange rate responses for each of the countries in each of the two groups, on impact and after 2 quarters. The exchange rate appreciation is in general 
lower in the case of interveners, with the important exception of Brazil (an outlier within the group).

Figure 7. Cross section of Exchange Rate Responses to a Global Capital Flows Shock

Step $t=0$

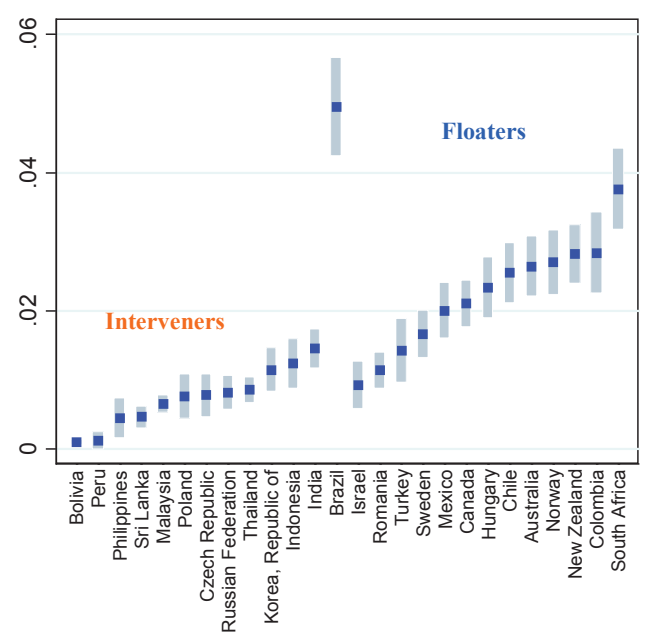

Step $t=2$

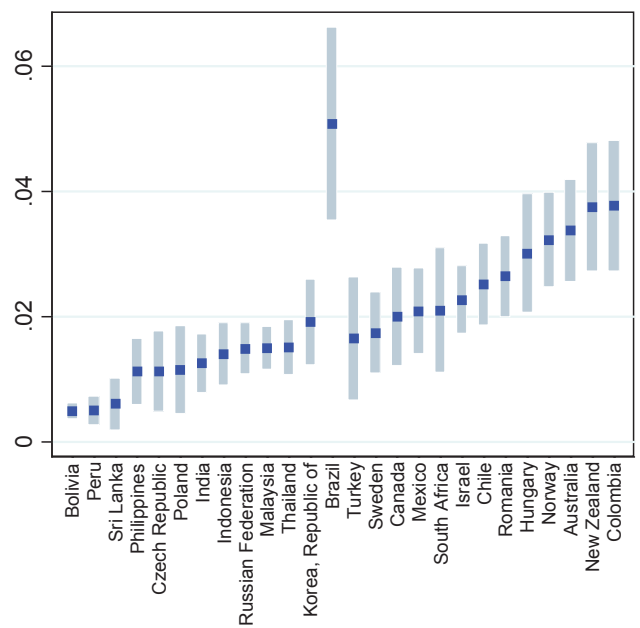

Note: Exchange rate impulse responses from individually estimated VAR models, at $\mathrm{t}=0$ and $\mathrm{t}=2$; grouped by floaters and interveners. One standard deviation bands are reported.

Moreover, as shown in Figure 8, there is a clear positive relationship between cumulative FXI and the average ER responses, both on impact and at 2-quarter horizon.

Figure 8.Exchange Rate and FXI Responses to a Global Capital Flows Shock

Step $t=0$

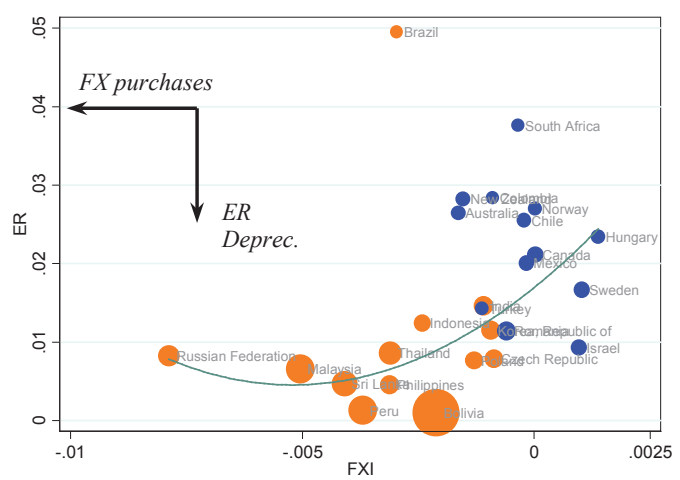

Step $t=2$

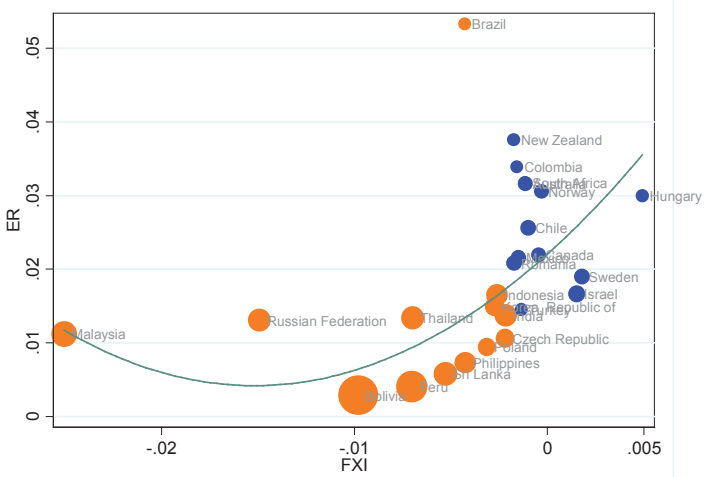

Note: Cumulative FXI (in percent of annual GDP) and average ER responses at $\mathrm{t}=0$ and $\mathrm{t}=2$; Circles are inversely proportional to the standard deviation of the ER response. Floaters are colored blue; interveners are colored orange. The line illustrates a (weighted) quadratic fit. 


\section{Real exchange rate and fixed exchange rate regimes}

The baseline specification focused on the bilateral nominal exchange rates. We now redo the analysis looking at the effects on real effective exchange rates. We look at three categories of countries: floaters and interveners, and, now, pegs. They are compared, two at a time, in Figure 9.

The top panel looks at floaters versus interveners, and thus replicates Figure 6, but using real exchange rates. The results are very similar to those in Figure 6.

The bottom panel looks at pegs versus interveners. Pegs experience a small real depreciation at the start, presumably because of the nominal appreciation of some of their trading partners. They appreciate somewhat afterwards, consistent with lags in inflation. Interestingly, pegs appear to carry out less intervention than interveners within the group of managed floaters (but not less than floaters). Pegs also display somewhat larger volumes of gross flows (in and out) than the other groups. 


\section{Figure 9. Impulse Responses to a Global Capital Flows Shock: Real Exchange Rates and Fixed Exchange Rate Regimes}

Panel (a). Floaters and Interveners

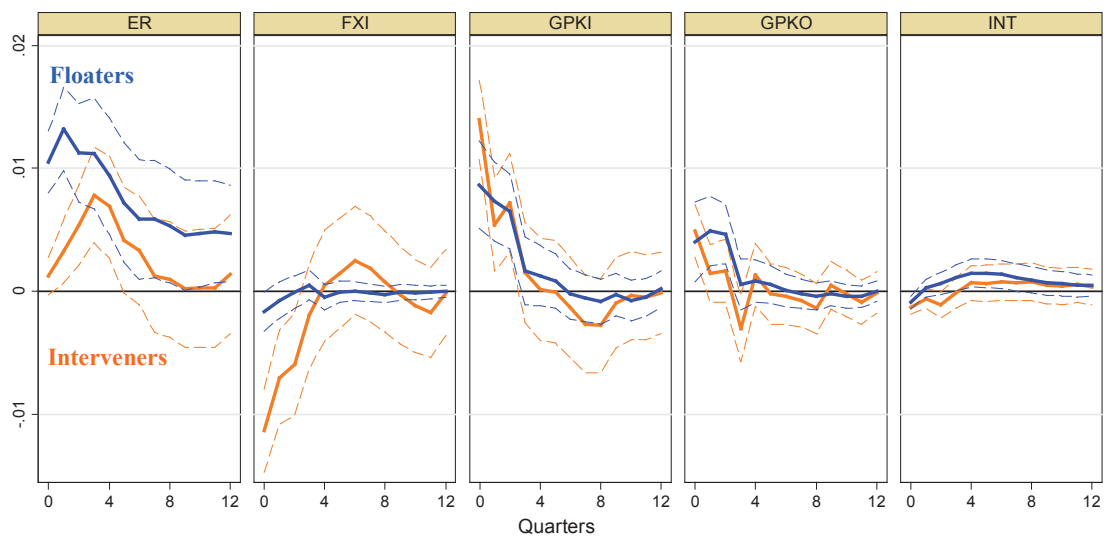

Panel (b). Pegs and Interveners
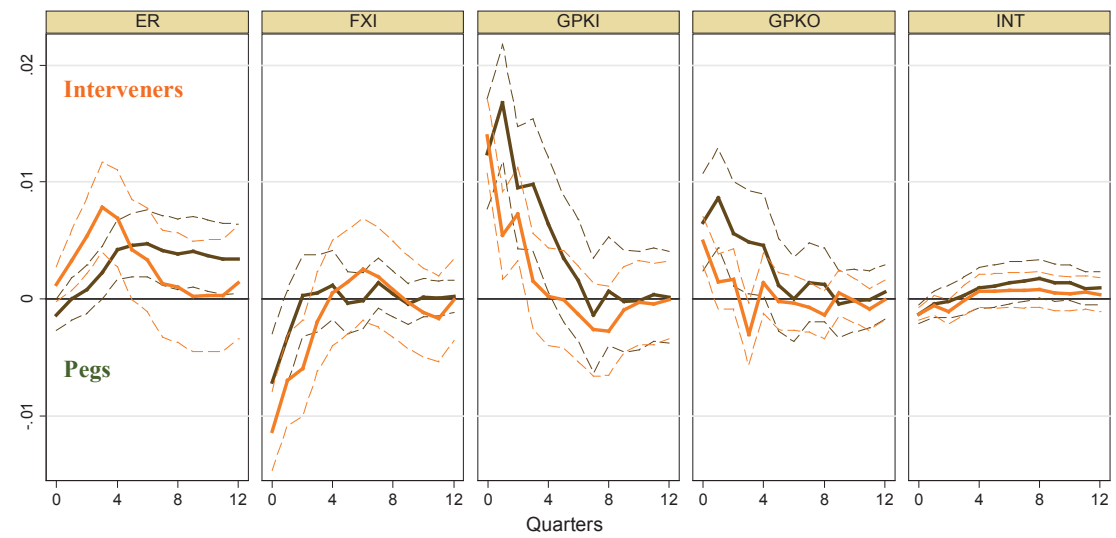

Note: The figure reports impulse response functions to a one standard deviation shock to the global capital inflow variable. For each group, a weighted average of impulse responses and their (60 percent) confidence bands is reported, with weights that are inversely proportional to the standard deviation of each impulse response.

\section{Robustness Checks}

In this section we conduct a series of robustness checks. While changes in the specification could lead to different country classifications (than those reported in Table 2), the classifications are quite stable, as shown in appendix Table A2. Appendix Figure A2 presents the results of robustness checks discussed here.

Proxy for FXI. In the baseline specification we relied on a proxy for FXI encompassing balance of payments data of changes in reserves and off balance sheet operations (derivatives). However, 
since the latter is not reported consistently across countries and time, we check the robustness of our results to using a narrower measure of FXI, based only on changes in reserves. The results are qualitatively similar to those of the baseline specification, and most countries remain as classified initially, with the exception of a few cases: Korea and Czech Republic become floaters, indicating that they tended, over the sample period, to rely more than other countries on off balance sheet operations. New Zealand and Romania, on the other hand, become interveners (see appendix Table A2).

Terms of trade. Terms of trade shocks are an important source of exchange rate variations, especially in commodity producing countries; and such shocks may be correlated with global capital flows. We extend the baseline specification to include country specific changes in terms of trade as a control. Results remain roughly unchanged.

Capital controls. A possible shortcoming of the baseline model relates to the fact that the specification does not control for the possible contemporaneous deployment of capital flow measures, due to the lack of sufficient comprehensive and high frequency (quarterly) data on capital controls. This may result in an upward bias in the estimated effect of FXI on the exchange rate (i.e., the seemingly dampening effect of the FXI on the exchange rate could be actually caused by uncontrolled-for capital control measures). To partly deal with such a possibility, we conduct the same exercise as in the baseline but excluding countries with frequent use of capital controls, as indicated by the standard deviation of their Quinn-Toyoda indexes during the sample period. Specifically, economies with indicators above the $70^{\text {th }}$ percentile are excluded. Results are quite similar to the baseline. In fact, we find that excluded countries mostly comprise pegs (Bulgaria, China, Estonia, Croatia) or floaters (Chile, Colombia, Hungary, Israel, Romania), possibly indicating a higher reliance on capital flow control as a substitute for foreign exchange intervention. ${ }^{16}$

\footnotetext{
${ }^{16}$ The measures of capital controls reflect the average behavior during the full sample period considered for the estimation of the VAR models.
} 
An additional concern related to capital controls is that the baseline results, especially those on gross outflows being less responsive in economies with heavy intervention, could simply reflect a higher (structural) degree of capital controls, precluding domestic investors from shifting assets across national borders in response to gross inflow shocks. To explore this, we check the robustness of the baseline results by excluding countries with high average levels of capital controls, during the period 1990-2012. In this case, the excluded countries correspond proportionally more to those initially classified as interveners (Brazil, India, Indonesia, Malaysia, Sri Lanka and Thailand) as opposed to floaters (Colombia, Mexico and South Africa). The main results, namely the dampening effect of FXI on the exchange rate and the patterns of gross flows are very similar to those of the baseline specification. The only significant difference is visible in the response of gross outflows, which show a greater differential between interveners and floaters.

Sterilized intervention. The inclusion of the domestic interest rate in the model should account for the effect of interest rate changes on the exchange rate, thus allowing to disentangle the separate effects of FXI and of the interest rate. To check the robustness of the results, however, we impose a more stringent condition, ruling out possible cases of unsterilized intervention. The latter cases are defined as those displaying a statistically significant negative response of the interest rate differential to global financial shocks (Brazil, Hungary, Indonesia, Philippines, and Russia in the benchmark results). The main results hold.

We also follow this approach with an alternative specification that introduces the domestic and the foreign interest rate separately in the model. In this case, the requirement of not displaying negative responses to a global capital flow shock applies to the domestic interest rate only. 
Hungary, Indonesia, Russia and Thailand are excluded under this criterion; and results remain similar to those of the benchmark specification.

Sensitivity to the global capital flows. We relax the criteria that exclude countries for not being sensitive to global capital flows shocks, by classifying non-peg countries into floaters and interveners. Again, results remain as in the benchmark classification.

Unconditional FXI regime classification. The baseline classification relies on the behavior of FXI conditional on a global flows shock. Alternatively, we can classify countries based on their unconditional intervention activities. Specifically, we consider as interveners those countries in the sample which satisfy the condition:

$$
\begin{gathered}
D_{i}(\text { intervener })=1 \text { if } \gamma_{i} \geq \tilde{\gamma} \\
\gamma_{i} \equiv \frac{\sum_{t=1}^{T_{i}}\left|F X I_{i, t}\right|}{\sum_{t=1}^{T_{i}}\left|G P K I_{i, t}\right|} \text { and } \tilde{\gamma} \equiv \operatorname{median}\left\{\gamma_{1} \ldots \gamma_{N}\right\}
\end{gathered}
$$

which is based on the relative degree of intervention in relationship to gross inflows over the sample period. Some countries - several of which were outliers in the baseline classificationchange categories. Guatemala, Israel and Norway become interveners, as opposed to not sensitive to the global financial cycle or floater under the conditional classification, reflecting reserve accumulation policies that are less sensitive to capital flow movements. ${ }^{17}$ New Zealand and Poland, on the other hand, become floaters. Results are similar to those of the baseline specification, except with regard to the differentiated pattern of gross flows between floaters and interveners, with respect to which the results are weaker than in the baseline. ${ }^{18}$

\footnotetext{
${ }^{17}$ Guatemala and Israel pursued, during part of the sample period, rule-based FXI policies. Norway's reserve accumulation may reflect developments related to oil revenue.

${ }^{18}$ Interestingly, the differentiated response of exchange rates between floaters and interveners is as stark under the unconditional classification as in the classification based on responses to a global capital flow shock. See results in Appendix Figure A3 and A4.
} 
VIX as the exogenous shock. As shown in Figure 5, our measure of global capital flows correlates closely with a standard measure of risk aversion, as captured by the VIX Index. ${ }^{19}$ Still, to ensure that our results do not depend on our specific measure, we re-estimate the model relying on the VIX index instead as the exogenous financial shock. Although the results are not directly comparable with those of the previous robustness checks since the magnitudes of the VIX and GKF shocks are not of the same magnitude, the results indicate again that intervention is effective in dampening the effects of external financial shocks on the exchange rate.

We also conduct as series of additional robustness checks (not reported), including using the first difference of the exchange rate out of possible concerns about non-stationarity; normalizing flow measures by trend GDP; using a broader measure of net official flows instead of central bank FXI; etc. Results remain quite close to those of the baseline specification.

\section{Conclusions}

We evaluate the effectiveness of sterilized intervention as an instrument to insulate countries from exchange rate pressures stemming from capital flow shocks. To deal with endogeneity issues, we rely on country-specific VAR estimations and exploit the cross-section variation of FXI responses to an exogenous capital flows shock. Consistent with the portfolio balance channel, we find evidence that larger intervention leads to less exchange rate appreciation in response to gross inflows. The magnitude of the effect is relevant from a macroeconomic perspective, suggesting that FXI can be a valid policy tool for macroeconomic management.

\footnotetext{
19 This is consistent with recent studies (e.g. Rey, 2013; de Carvalho Filho, 2014), which find the VIX to be a good proxy for global financial flows.
} 


\section{REFERENCES}

Adler, Gustavo and Camilo E. Tovar, 2014, "Foreign Exchange Interventions and their Impact on Exchange Rate Levels," Monetaria, Centro de Estudios Monetarios Latinoamericanos, vol. $0(1)$, pages $1-48$.

Adler, Gustavo, Marie Louise Djigbenou and Sebastian Sosa, 2015, “Global Financial Shocks and Foreign Asset Repatriation: Do Local Investors Play a Stabilizing Role?'Journal of International Money and Finance (forthcoming).

Agénor, Pierre, K. Alper and L. Pereira da Silva, 2012, “Sudden Floods, Macroprudential Regulation and Stability in an Open Economy," mimeo.

Aizenman, Joshua and Jaewoo Lee, 2008, "Financial versus Monetary Mercantilism: Long-Run View of Large International Reserves Hoarding," World Economy 31(5): 593-611.

Alberola, Enrique, Aitor Erce, and Jose Maria Serena, 2012, "International Reserves and Gross Capital Flows. Dynamics during Financial Stress" Banco de España Working Paper 1211.

Bayoumi, Tamim, Joseph E. Gagnon and Christian Saborowski, 2014, “Official Financial Flows, Capital Mobility, and Global Imbalances,” IMF Working Paper 14/199.

Benes, Jaromir, Andrew Berg, Rafael A. Portillo and David Vavra, 2012. "Modeling Sterilized Intervention and Balance Sheet Effects of Monetary Policy,” IMF Working Paper 13/11.

Bluedorn, John C., Rupa. Duttagupta, Jaime Guajardo, and Petia Topalova, 2013, "Capital Flows are Fickle: Anytime, Anywhere," IMF Working Paper No. 13/183.

Branson, W.H., Henderson, D.W., 1985, “The Specification and Influence of Asset Markets,” In: Handbook of International Economics, vol. 2.

Broner, Fernando, Tatiana Didier, Aitor Erce, and Sergio Schmukler. 2013. "Gross Capital Flows: Dynamics and Crises," Journal of Monetary Economics, vol. 60 (1), 2013, Pages 113133

Bruno, V., and H. Shin, 2012, "Capital flows, Cross-border Banking and Global Liquidity," NBER Working Paper 19038. Cambridge, United States: National Bureau of Economic Research. 
Calvo, Guillermo, L. Leiderman and C. Reinhart, 1993. "Capital Inflows and Real Exchange Rate Appreciation in Latin America: The Role of External Factors," IMF Staff Papers 40: 108-151.

Calderón, C. and M. Kubota, 2013, "Sudden stops: Are Global and Local Investors Alike?" Journal of International Economics, vol. 89 (1), pages 122-142.

Canales-Kriljenko, Jorge Iván, 2003. "Foreign Exchange Intervention in Developing and Transition Economies: Results of a Survey," IMF Working Paper 03/95.

Cavallo, Eduardo A., Andrew Powell, Mathieu Pedemonte, and Pilar Tavella, 2013, “A New Taxonomy of Sudden Stops: Which Sudden Stops Should Countries be Most Concerned About?” Inter-American Development Bank Working Paper 82148.

Cowan, K., J. De Gregorio, A. Micco, and C. Neilson, 2008, "Financial diversification, sudden stops, and sudden starts," in Cowan, K., S. Edwards, and R. Valdes, (Eds.), Current Account and External Finance. Central Bank of Chile, Santiago, Chile, pp. 159-194.

De Bock, Reinout, and Irineu de Carvalho Filho, 2015, "The Behavior of Currencies during Risk-off Episodes," Journal of International Money and Finance, vol. 53: 218-234.

de Carvalho Filho, Irineu, 2014, "Risk-off Episodes and Swiss Franc Appreciation: the Role of Capital Flows," German Economic Review (forthcoming).

Domaç, Ilker, and Alfonso Mendoza, 2004, "Is There Room for Foreign Exchange Interventions Under an Inflation Targeting Framework? Evidence from Mexico and Turkey," World Bank Policy Research Working Paper No. 3288, April.

Dominguez, Kathryn M.E., Rasmus Fatum and Pavel Vacek, 2013, "Do Sales of Foreign Exchange Reserves Lead to Currency Appreciation?" Journal of Money, Credit and Banking, vol. $45,5,867-890$.

Dominguez, Kathryn M.E., 1998, "Central Bank Intervention and Exchange Rate Volatility", Journal of International Money and Finance, 17, 1, 161-190.

Dominguez, Kathryn M. and Jeffrey A. Frankel, 1993a, "Does Foreign Exchange Intervention Work?" Washington, DC: Institute of International Economics. 
Dominguez, Kathryn M. and Jeffrey A. Frankel, 1993b, "Foreign Exchange Intervention: An Empirical Assessment," in On Exchange Rates. Jeffrey A. Frankel, ed. Cambridge, MA: MIT Press.

Dominguez, Kathryn M.E. and Jeffrey Frankel, 1993c, "Does Foreign Exchange Intervention Matter? The Portfolio Effect," American Economic Review, Vol. 83, No. 5, 1356-1369.

Dominguez, Kathryn M.E. and Peter Kenen, 1992, "Intramarginal Intervention in the EMS and the Target-Zone Model of Exchange Rate Behavior," European Economic Review, Vol 36, $1523-1532$.

Dominguez, Kathryn M.E., 1990, "Market Responses to Coordinated Central Bank Intervention", Carnegie Rochester Series on Public Policy, Vol. 32, 121-164.

Forbes, K. and F. Warnock, 2012, “Capital flow Waves: Surges, Stops, Flight and Retrenchment," Journal of International Economics, vol. 88 (2): 235-251.

Gabaix, Xavier and Matteo Maggiori, 2014, "International Liquidity and Exchange Rate Dynamics," mimeo.

Gagnon, Joseph, 2013, “The Elephant Hiding in the Room: Currency Intervention and Trade Imbalances,” Working Paper No.13-2. Washington: Peterson Institute for International Economics.

Gagnon, Joseph, 2012, “Combating Widespread Currency Manipulation,” Peterson Institute for International Economics, Policy Brief 12-19, July 2012.

Ghosh, Atish R., Jonathan D. Ostry and Charalambos G. Tsangarides, 2012, "Shifting Motives: Explaining the Buildup in Official Reserves in Emerging Markets since the 1980s," IMF Working Paper 12/34.

Ghosh, Atish R., Jonathan D. Ostry, and Marcos Chamon, 2015, “Two Targets, Two Instruments: Monetary and Exchange Rate Policies in Emerging Market Economies," Journal of International Money and Finance.

Ghosh, Atish R. 1992, “Is It Signalling? Exchange Intervention and the Dollar-Deutschemark Rate," Journal of International Economics. 32:3-4, pp. 201-20. 
Guimarães-Filho, Roberto F., and Cem Karacadag, 2004, "The Empirics of Foreign Exchange Intervention in Emerging Market Countries: the Cases of Mexico and Turkey," IMF Working Paper 04/123.

Hau, Harald, Massimo Massa and Joel Peress, 2009, "Do Demand Curves for Currencies Slope Down? Evidence from the MSCI Global Index Change," The Review of Financial Studies 23(4): 1681-1717.

Henderson, Dale W. and Kenneth Rogoff, 1981, "New Foreign Asset Positions and Stability in a World Portfolio Balance Model,” International Finance Discussion Papers 178, Board of Governors of the Federal Reserve System (U.S.).

Humala, Alberto and Gabriel Rodriguez, 2010, "Foreign Exchange Intervention and Exchange Rate Volatility in Peru," Applied Economics Letters, 17, 1485-1491.

Ilzetzki, Ethan, Carmen M. Reinhart and Kenneth S. Rogoff, 2011, "The Country Chronologies and Background Material to Exchange Rate Arrangements into the 21st Century: Will the Anchor Currency Hold?" mimeo.

Jeanne, Olivier and Romain Ranciere, 2011, "The Optimal Level of International Reserves For Emerging Market Countries: A New Formula and Some Applications," The Economic Journal Volume 121, Issue 555, pp. 905-930.

Kamil, Herman, 2008, “Is Central Bank Intervention Effective Under Inflation Targeting Regimes? The Case of Colombia," IMF Working Paper 08/88.

Kouri, P., 1983, "Balance of Payments and the Foreign Exchange Market: a Dynamic Partial Equilibrium Model,” In: Bhandari, J., Putnam, B. (Eds.), Economic Interdependence and Flexible Exchange Rates. MIT Press, Cambridge, MA.

Kumhof, Michael, 2010, “On the Theory of Sterilized Foreign Exchange Intervention,” Journal of Economic Dynamics and Control 34: 1403-1420.

Menkhoff, Lukas, 2010, "High-Frequency Analysis of Foreign Exchange Interventions: What Do We Learn?” Journal of Economic Surveys 24(1): 85-112.

Menkhoff, Lukas, 2012, "Foreign Exchange Intervention in Emerging Markets: A Survey of Empirical Studies,” Leibniz Universität Hannover Discussion Paper No.498. 
Milesi-Ferretti, Gian-Maria and Cédric Tille, 2011, "The Great Retrenchment: International Capital Flows during the Global Financial Crisis," Economic Policy April 2011: 289-346.

Moreno, Ramon, 2005, “Motives for Intervention,” BIS Papers No. 24: 4-18.

Neely, Christopher J., 2008, “Central Bank Authorities’ Beliefs about Foreign Exchange Intervention," Journal of International Money and Finance 27: 1-25.

Neely, Christoper J., 2005, “An Analysis of Recent Studies of the Effect of Foreign Exchange Intervention,” Federal Reserve Bank of St. Louis Review, 87, 685-717.

Powell, A., Ratha, D., Mohapatra, S., 2002, "Capital inflows and capital outflows: measurement, determinants, consequences," Business School Working Paper, Universidad Torcuato Di Tella.

Quinn, Dennis P. and A. Maria Toyoda, 2008, "Does Capital Account Liberalization Lead to Growth?” The Review of Financial Studies 21(3): 1403-1449.

Reinhart, Carmen M. and Vincent R. Reinhart, 2008, “Capital Inflows and Reserve Accumulation: The Recent Evidence," NBER Working Paper 13842.

Rey, Helene, 2013, "Dilemma not Trilemma: The Global Financial Cycle and Monetary Policy Independence," mimeo.

Rincón, Hernán and Jorge Toro, 2011, “Are Capital Controls and Central Bank Intervention Effective?” Borradores de Economía Núm.625, Banco de la República, Colombia.

Rothenberg, A. and F. Warnock, 2011, "Sudden flight and true sudden stops," Review of International Economics 19 (3) (2011), pp. 509-524

Sarno, Lucio and Mark Taylor, 2001, "Official Intervention in the Foreign Exchange Market: Is It Effective and, If So, How Does It Work?" Journal of Economic Literature 39: 839-868.

Schindler, Martin. 2009, "Measuring Financial Integration: A New Data Set." IMF Staff Papers 56, no. 1: 222-238.

Stone, Mark R., W. Christopher Walker and Yosuke Yasui, 2009, "From Lombard Street to Avenida Paulista: Foreign Exchange Liquidity Easing in Brazil in Response to the Global Shock of 2008-09," IMF Working Paper 09/259. 
Tapia, Matias and Andrea Tokman, 2004, "Effects of Foreign Exchange Intervention under Public Information: The Chilean Case," Economía, 4:2, 215-256. 
Table A1

\begin{tabular}{|l|l|}
\hline Country & Sample period \\
\hline Brazil & 1998Q4 onwards \\
\hline Bulgaria & 1996Q4 onwards \\
\hline Canada & 2002Q2 onwards \\
\hline Chile & 1992Q2 onwards \\
\hline Croatia & 1994Q4 onwards \\
\hline Estonia & 1992Q3 to 2010Q4 \\
\hline Indonesia & 1992Q2 onwards \\
\hline Korea & 1998Q3 onwards \\
\hline Latvia & 1994Q4 onwards \\
\hline Lithuania & 1995Q2 onwards \\
\hline Peru & 1994Q4 onwards \\
\hline Philippines & 1998Q1 onwards \\
\hline Poland & 1995Q3 onwards \\
\hline Romania & 2001Q2 onwards \\
\hline Russian Federation & 2000Q1 onwards \\
\hline South Africa & 1995Q2 onwards \\
\hline Sweden & 1993Q1 onwards \\
\hline Thailand & 1999Q1 onwards \\
\hline Turkey & 2003Q2 onwards \\
\hline
\end{tabular}

Table A2. De facto FXI Regime - Classification of Countries across Specifications

\begin{tabular}{|c|c|c|c|c|c|c|c|c|c|c|c|}
\hline \multirow[b]{2}{*}{ IFS code } & \multirow[b]{2}{*}{ Country Name } & \multicolumn{3}{|c|}{ Excluding Off- } & \multirow{2}{*}{$\begin{array}{l}\text { Capital } \\
\text { Controls }\end{array}$} & \multirow{2}{*}{$\begin{array}{c}\text { Capital } \\
\text { Controls (2) }\end{array}$} & \multirow[b]{2}{*}{ Sterilized FXI } & \multirow{2}{*}{$\begin{array}{l}\text { Sterilized FXI } \\
\text { (2) }\end{array}$} & \multirow{2}{*}{$\begin{array}{l}\text { Sensitivity } \\
\text { Criterion }\end{array}$} & \multirow{2}{*}{$\begin{array}{l}\text { Unconditional } \\
\text { Classif. }\end{array}$} & \multirow[b]{2}{*}{ VIX } \\
\hline & & Baseline & BS FXI & Terms of trade & & & & & & & \\
\hline 128 & Denmark & Peg & Peg & Peg & Peg & Peg & Peg & Peg & Peg & Peg & Peg \\
\hline 142 & Norway & Floater & Floater & Floater & Floater & Floater & Floater & Floater & Floater & Intervener & Intervener \\
\hline 144 & Sweden & Floater & Floater & Floater & Floater & Floater & Floater & Floater & Floater & Floater & Not Sensitive \\
\hline 156 & Canada & Floater & Floater & Floater & Floater & Floater & Floater & Floater & Floater & Floater & Floater \\
\hline 186 & Turkey & Floater & Floater & Floater & Floater & Floater & Floater & Floater & Floater & Floater & Floater \\
\hline 193 & Australia & Floater & Floater & Floater & Floater & Floater & Floater & Floater & Floater & Floater & Floater \\
\hline 196 & New Zealand & Floater & Intervener & Intervener & Floater & Floater & Intervener & Intervener & Intervener & Floater & Floater \\
\hline 199 & South Africa & Floater & Floater & Floater & Floater & $\ldots$ & Floater & Floater & Floater & Floater & Intervener \\
\hline 218 & Bolivia & Intervener & Intervener & Intervener & Intervener & Intervener & Intervener & Intervener & Intervener & Intervener & Intervener \\
\hline 223 & Brazil & Intervener & Intervener & Intervener & Intervener & $\ldots$ & & Intervener & Intervener & Intervener & Floater \\
\hline 228 & Chile & Floater & Floater & Floater & & Floater & Floater & Floater & Floater & Floater & Floater \\
\hline 233 & Colombia & Floater & Floater & Floater & & & Floater & Floater & Floater & Floater & Intervener \\
\hline 258 & Guatemala & Not Sensitive & Floater & Not Sensitive & Not Sensitive & Not Sensitive & Not Sensitive & Not Sensitive & Floater & Intervener & Intervener \\
\hline 273 & Mexico & Floater & Floater & Floater & Floater & & Floater & Floater & Floater & Floater & Floater \\
\hline 293 & Peru & Intervener & Intervener & Intervener & Intervener & Intervener & Intervener & Intervener & Intervener & Intervener & Not Sensitive \\
\hline 436 & Israel & Floater & Floater & Floater & & Floater & Floater & Floater & Floater & Intervener & Floater \\
\hline 524 & Sri Lanka & Intervener & Intervener & Intervener & Intervener & $\ldots$ & Intervener & Not Sensitive & Intervener & Intervener & Intervener \\
\hline 534 & India & Intervener & Intervener & Intervener & Intervener & $\ldots$ & Intervener & Intervener & Intervener & Intervener & Floater \\
\hline 536 & Indonesia & Intervener & Intervener & Intervener & Intervener & $\ldots$ & & & Intervener & Intervener & Floater \\
\hline 542 & Korea, Republic of & Intervener & Floater & Intervener & Intervener & Intervener & Intervener & Intervener & Intervener & Intervener & Intervener \\
\hline 548 & Malaysia & Intervener & Intervener & Intervener & Intervener & $\ldots$ & Intervener & Intervener & Intervener & Intervener & Intervener \\
\hline 566 & Philippines & Intervener & Intervener & Intervener & Intervener & Intervener & . & Intervener & Intervener & Intervener & Intervener \\
\hline 578 & Thailand & Intervener & Intervener & Intervener & Intervener & & Intervener & & Intervener & Intervener & Intervener \\
\hline 918 & Bulgaria & Peg & Peg & Peg & & Peg & Peg & Peg & Peg & Peg & Peg \\
\hline 922 & Russian Federation & Intervener & Intervener & Intervener & Intervener & Intervener & & & Intervener & Intervener & Intervener \\
\hline 924 & China,P.R.: Mainland & Peg & Peg & Peg & Peg & Peg & Peg & Peg & Peg & Peg & Peg \\
\hline 926 & Ukraine & Peg & Peg & Peg & Peg & $\ldots$ & Peg & Peg & Peg & Peg & Peg \\
\hline 935 & Czech Republic & Intervener & Floater & Floater & $\ldots$ & Floater & Floater & Intervener & Floater & Floater & Not Sensitive \\
\hline 939 & Estonia & Peg & Peg & Peg & $\ldots$ & Peg & Peg & Peg & Peg & Peg & Peg \\
\hline 941 & Latvia & Peg & Peg & Peg & Peg & Peg & Peg & Peg & Peg & Peg & Peg \\
\hline 944 & Hungary & Floater & Floater & Floater & $\ldots$ & Floater & & & Floater & Floater & Floater \\
\hline 946 & Lithuania & Peg & Peg & Peg & Peg & Peg & Peg & Peg & Peg & Peg & Peg \\
\hline 960 & Croatia & Peg & Peg & Peg & $\ldots$ & Peg & Peg & Peg & Peg & Peg & Peg \\
\hline 964 & Poland & Intervener & Intervener & Not Sensitive & Intervener & Intervener & Intervener & Intervener & Intervener & Floater & Not Sensitive \\
\hline 968 & Romania & Floater & Intervener & Not Sensitive & $\ldots$ & Intervener & Intervener & Intervener & Intervener & Intervener & Intervener \\
\hline
\end{tabular}


Figure A1. Responses to a Global Capital Flow Shock

Step $t=0 \quad$ Step $t=2$

Panel (a). INT responses to a global capital flow shock
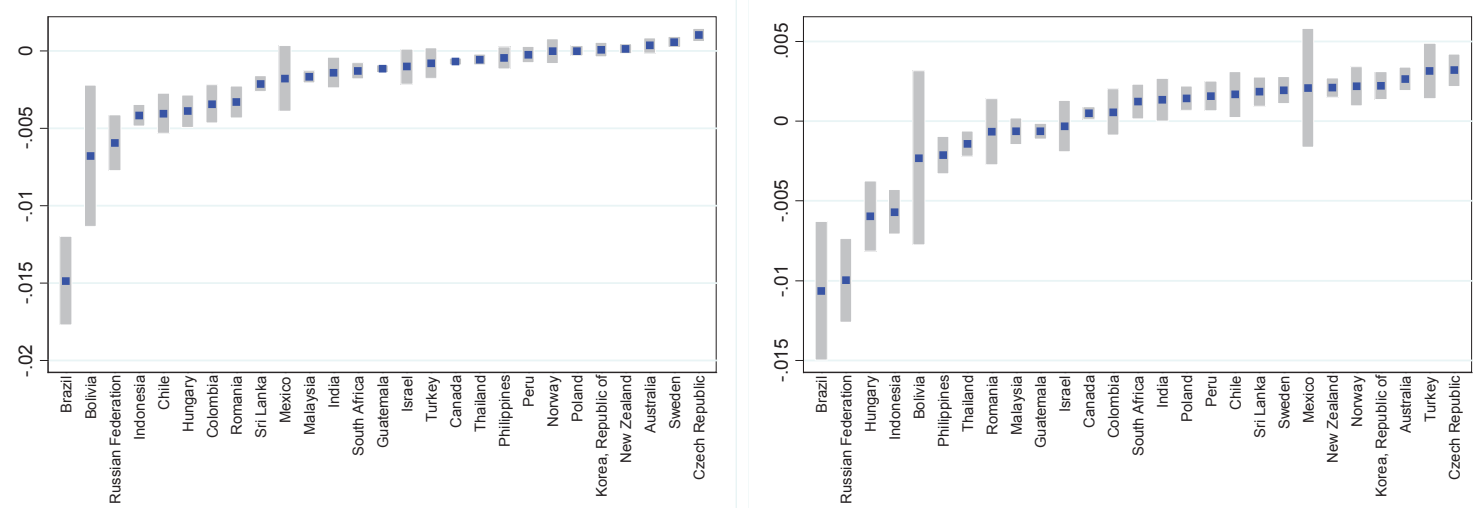

Panel (b). GPKO responses to a global capital flow shock
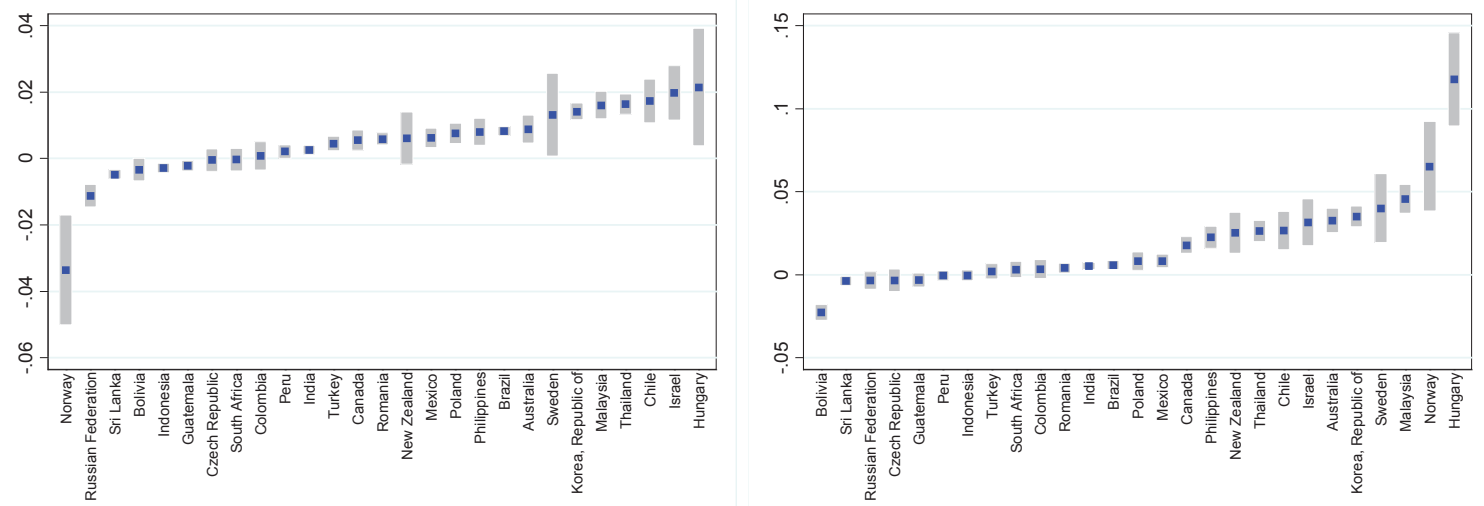

Note: Cumulative impulse responses from individually estimated VAR models, at $\mathrm{t}=0$ and $\mathrm{t}=2$; except for INT, which is noncumulative. One standard deviation bands are reported. 
Figure A2. Robustness Check. Responses of Floaters and Interveners to a Global Capital Flow Shock (non-peg economies)

Step $t=0$

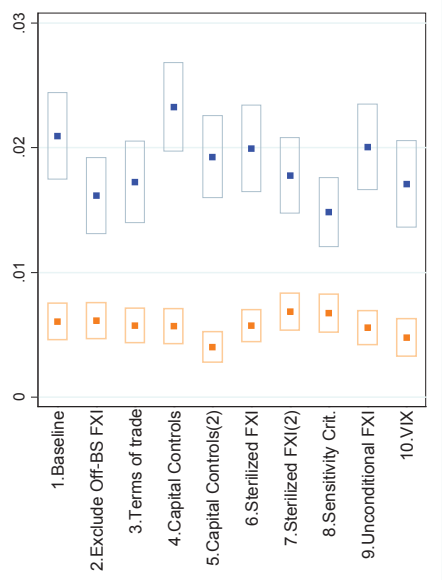

Step $t=2$

Panel (a). ER responses

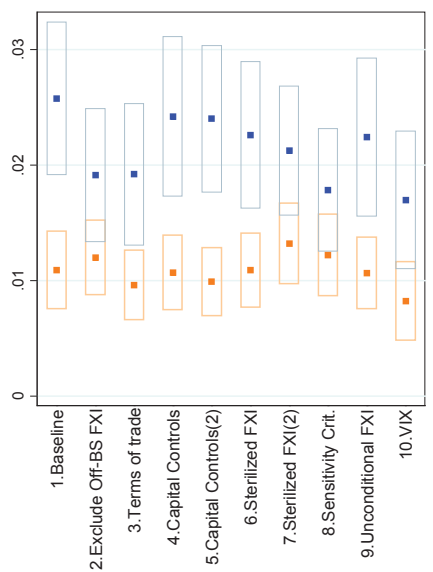

Panel (b). GPKI cumulative responses
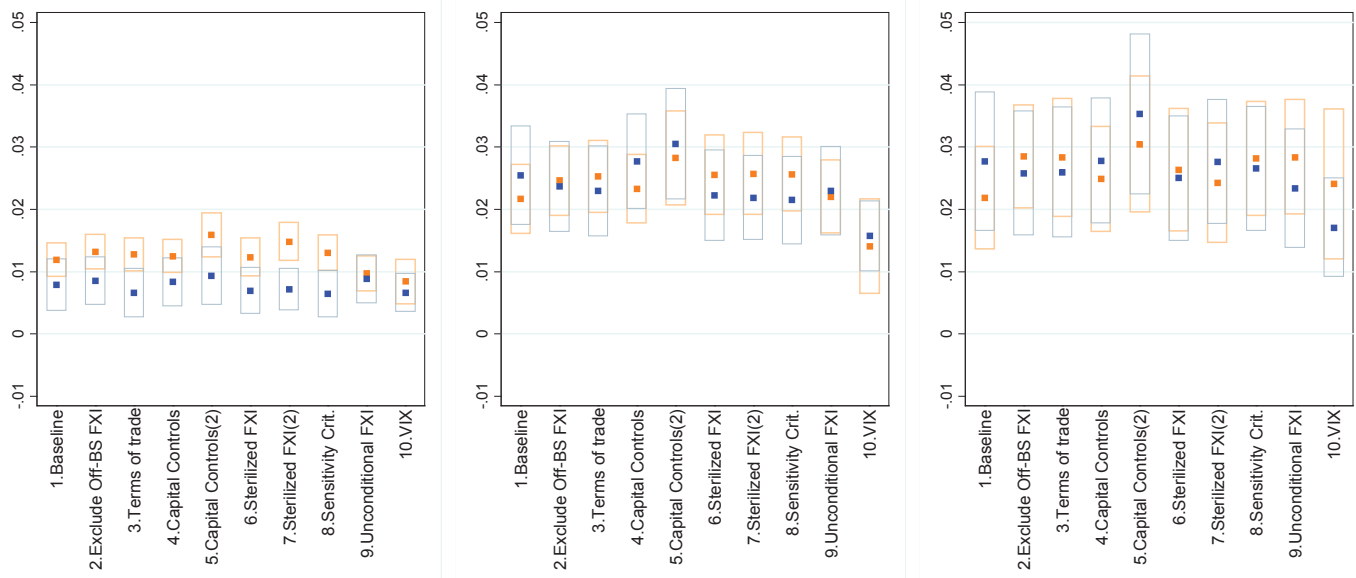

Panel (c). GPKO cumulative responses
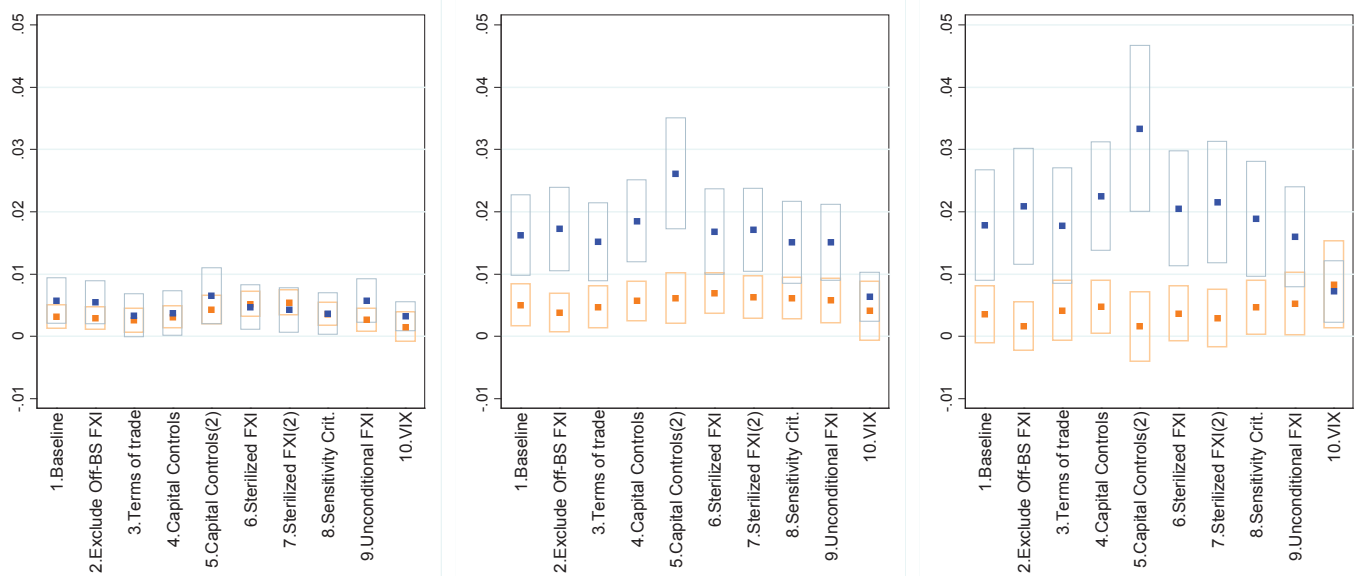

Note: The figure reports results from alternative specifications, as described in the main text, for floaters (in blue) and interveners (in orange). For each of them, the estimated (weighted) average response for floaters and interveners are shown, at $\mathrm{t}=\{0,2,4\}$. 
Figure A2 (continued). Robustness Check. Responses of Floaters and Interveners to a Global Capital Flow Shock (non-peg economies)

Step $t=0$
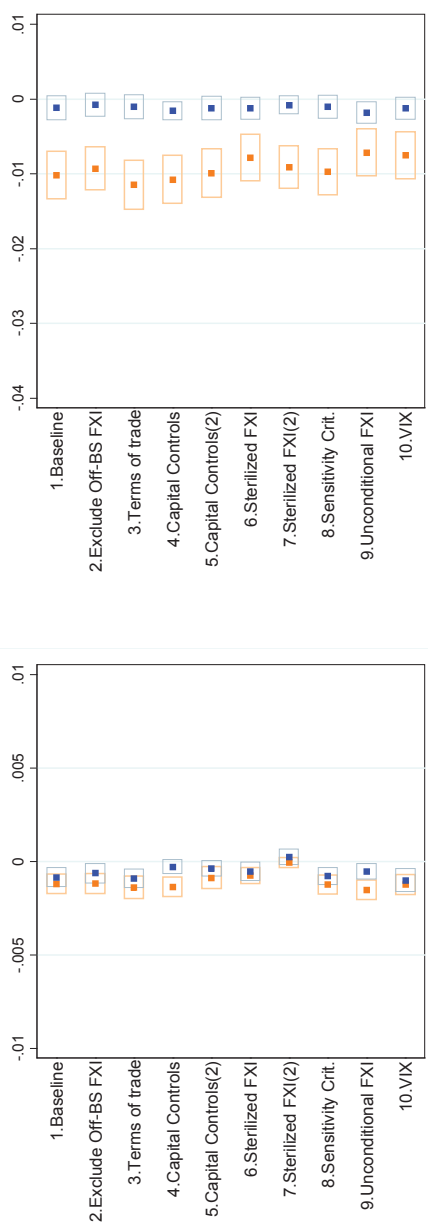

Step $t=2$

Panel (d). FXI cumulative responses

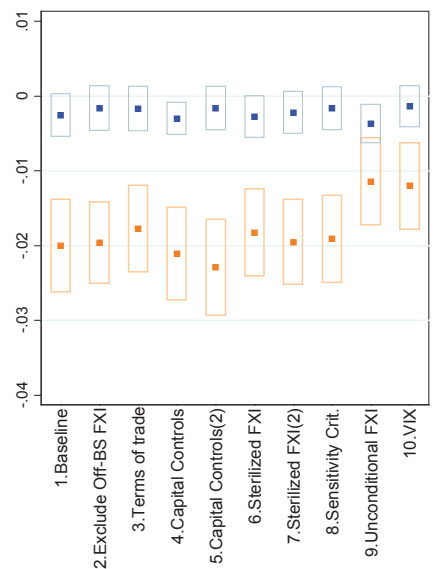

Panel (e). INT responses

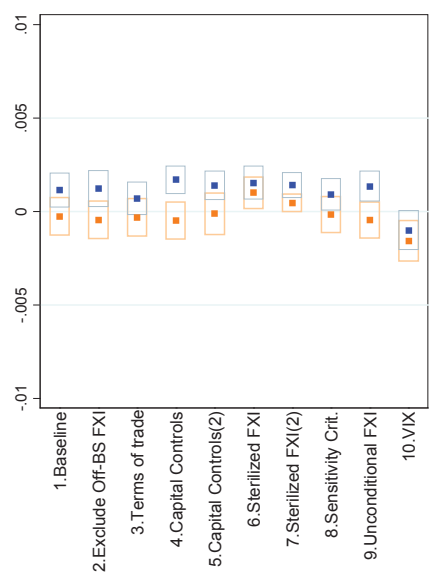

Step $=4$
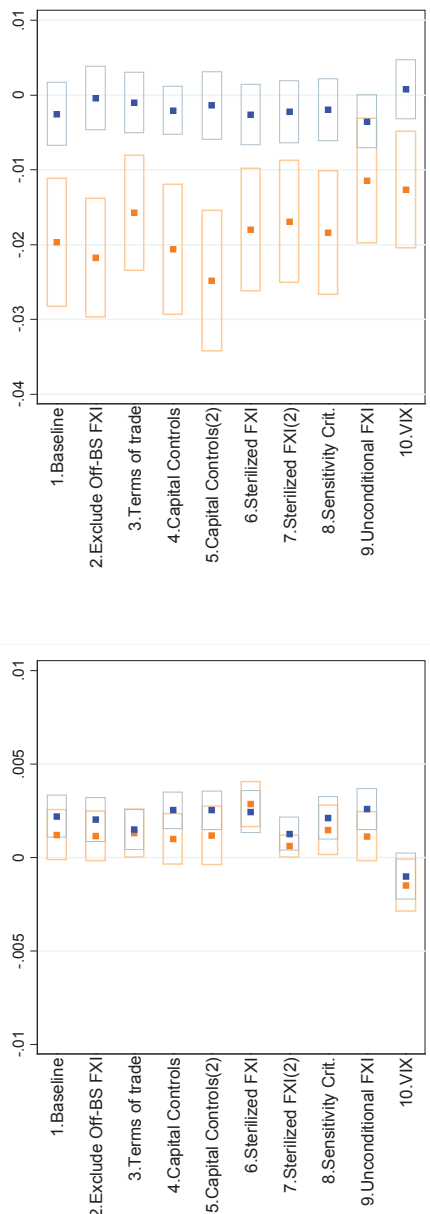

Note: The figure reports results from alternative specifications, as described in the main text, for floaters (in blue) and interveners (in orange). For each of them, the estimated (weighted) average response for floaters and interveners are shown, at $\mathrm{t}=\{0,2,4\}$. 
Figure A3. Impulse Responses to a Global Capital Flow Shock-Unconditional FXI Regime Classification

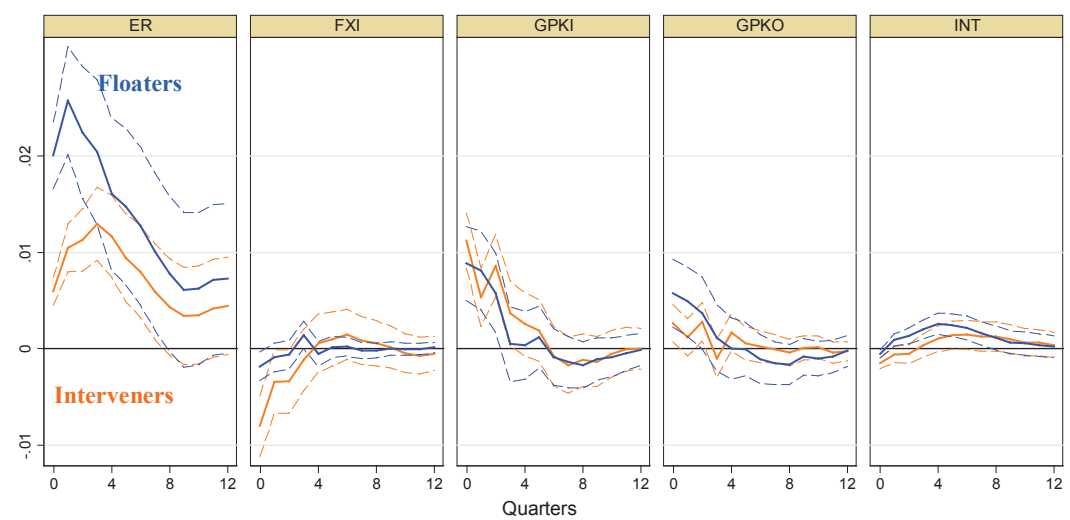

Note: Impulse response functions to a one standard deviation shock to the global capital flow variable. For each group, weighted averages of the impulse responses and confidence bands are reported, with weights that are inversely proportional to the standard deviation of each impulse response.

Figure A4. Cross section of Exchange Rate Responses to a Global Capital Flows Shock-Unconditional FXI Regime Classification

Step $t=0$

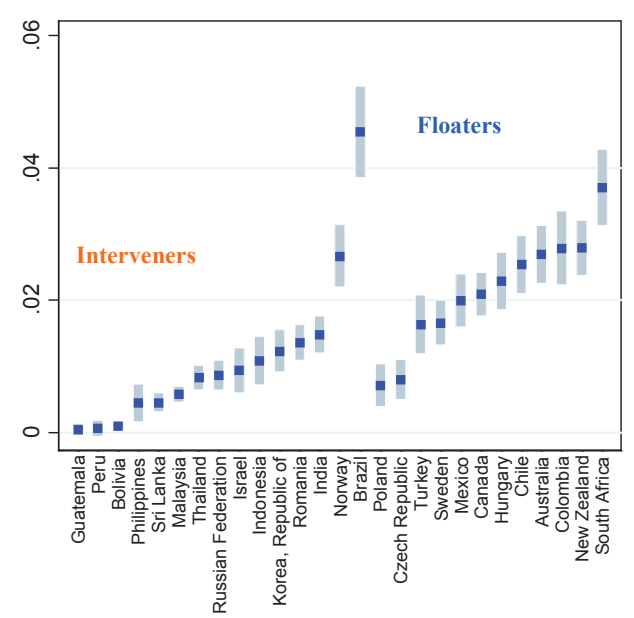

Step $t=2$

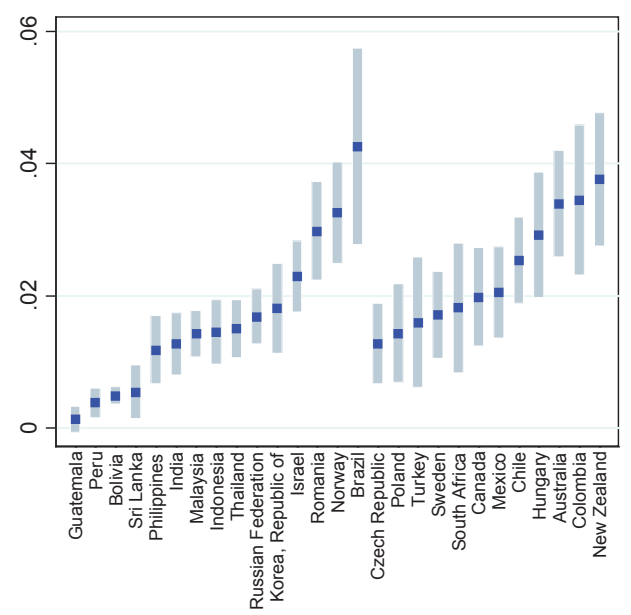

Note: Exchange rate impulse responses from individually estimated VAR models, at $\mathrm{t}=0$ and $\mathrm{t}=2$; grouped by floaters and interveners. One standard deviation bands are reported. 